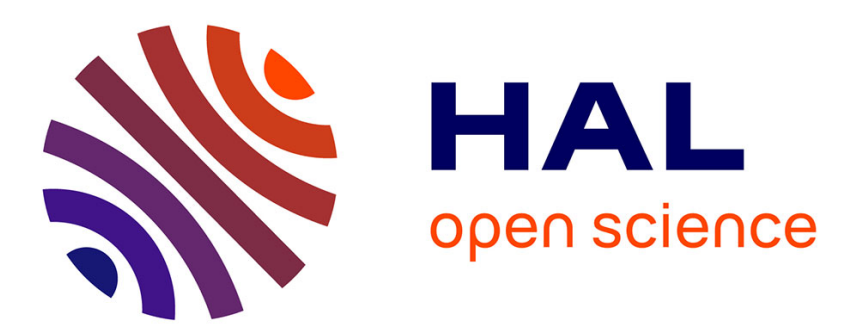

\title{
Quantum-Chemical Modeling of the First Steps of the Strecker Synthesis: From the Gas-Phase to Water Solvation
}

\author{
Vanessa Riffet, Gilles Frison, Guy Bouchoux
}

\section{To cite this version:}

Vanessa Riffet, Gilles Frison, Guy Bouchoux. Quantum-Chemical Modeling of the First Steps of the Strecker Synthesis: From the Gas-Phase to Water Solvation. Journal of Physical Chemistry A, 2018, 122 (6), pp.1643-1657. 10.1021/acs.jpca.7b10534 . hal-01927653

\section{HAL Id: hal-01927653 \\ https://hal.science/hal-01927653}

Submitted on 11 Jun 2019

HAL is a multi-disciplinary open access archive for the deposit and dissemination of scientific research documents, whether they are published or not. The documents may come from teaching and research institutions in France or abroad, or from public or private research centers.
L'archive ouverte pluridisciplinaire HAL, est destinée au dépôt et à la diffusion de documents scientifiques de niveau recherche, publiés ou non, émanant des établissements d'enseignement et de recherche français ou étrangers, des laboratoires publics ou privés. 


\title{
Quantum-Chemical Modeling of the First Steps of the Strecker Synthesis: from the Gas-Phase to Water Solvation
}

\author{
V. Riffet, G. Frison and G. Bouchoux* \\ LCM. CNRS. Ecole polytechnique, Université Paris-Saclay, 91128 Palaiseau, France.
}

\begin{abstract}
The two first steps of the Strecker synthesis of glycine, namely (a) addition of ammonia to formaldehyde to give aminomethanol and (b) its dehydration leading to methaneimine, is studied using high level quantum chemistry computations (G3B3). Water solvation is modeled by considering the effect of adding a discrete number of active or passive molecules of water (up to four) and by immersing the identified water-solute complexes in a conductorlike polarizable continuum solvent model. Activation of the reactants by protonation is also examined. Exhaustive search of microhydrated neutral and protonated aminomethanol has been performed using a combination of hierarchical and genealogical approaches. Critical energies associated with all the elementary reaction steps were estimated using the accurate G3B3 composite method thus providing benchmarks to discuss the possible occurence of Strecker synthesis in prebiotic chemistry.
\end{abstract}

\section{Corresponding author:}

Professor Guy Bouchoux, Email address: guv.bouchouxapolytechnique.edu 


\section{INTRODUCTION}

The Strecker reaction ${ }^{1}$ is probably the most straightforward route from simple compounds such as ketone, aldehyde, ammonia and hydrogen cyanide to $\alpha$-aminoacids. For this reason, it has been extensively studied ${ }^{2}$ and reviewed ${ }^{3-5}$. Briefly, the Strecker synthesis proceeds through several successive steps as depicted in Scheme 1: (a) addition of ammonia to an aldehyde RCHO giving rise to the corresponding aminoalcohol $\mathrm{RCH}(\mathrm{OH}) \mathrm{NH}_{2}$, (b) deshydration of the later producing the imine $\mathrm{RCHNH}$, then, (c) reaction of the imine with hydrogen cyanide leading to formation of an $\alpha$-aminonitrile $\mathrm{RCH}\left(\mathrm{NH}_{2}\right) \mathrm{CN}$. Additionally, in aqueous solution, $\alpha$-aminonitrile formation is accompanied by a series of other processes constituting a complex network of equilibrated reactions ${ }^{2}$ from which emerge two noticeable irreversible pathways: (d) the hydrolytic transformation leading to $\alpha$-amino acid, and (e) the reaction with $\mathrm{CO}_{2}$ giving hydantoins through the Bücherer-Berg reaction ${ }^{6}$.

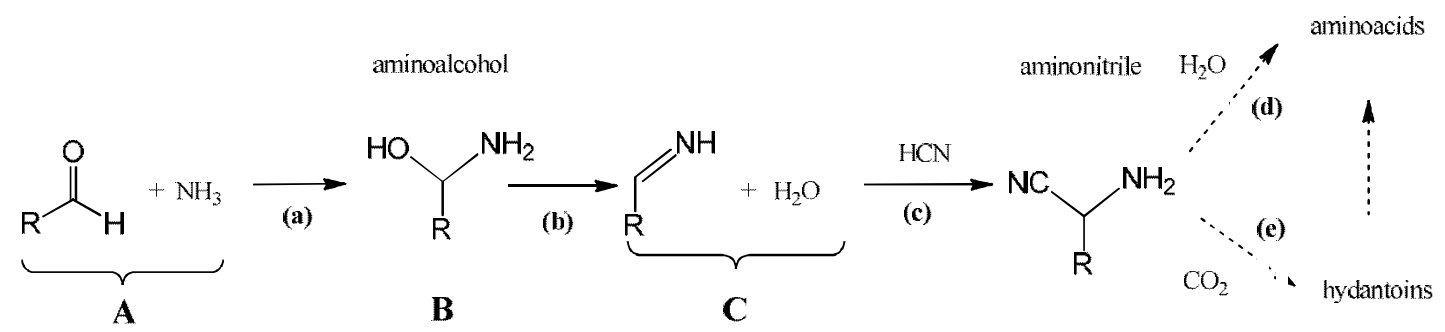

Scheme 1. A simplified view of the Strecker synthesis of amino acids.

Occurrence of the abiotic formation of $\alpha$-amino acids on the early Earth through the Strecker synthesis has been first advocated by Miller ${ }^{7}$. This hypothesis has been retained by a number of researchers who suggested that this pathway may be efficient in many other environments in the Universe ${ }^{8-19}$. Indeed, since its reactants (hydrogen cyanide, ammonia and aldehydes such as formaldehyde and acetaldehyde) have been identified in interstellar or circumstellar media ${ }^{20,21}$, the occurrence of Strecker reaction can be conceivable as a synthetic pathway in interstellar media, even in the gas-phase or on the surface of ice grains. Moreover, the presence of imino-diacids (usual by-products of this synthesis route) in carbonaceous chondrites has been considered as an indication that the Strecker reaction has been involved in the formation of amino acids in the parent bodies of this family of meteorites ${ }^{9,18,22}$. Recently, laboratory experiments on interstellar ice analogs show that aminomethanol, $\mathrm{HOCH}_{2} \mathrm{NH}_{2}$, (in parallel with hydroxyacetonitrile, $\mathrm{HOCH}_{2} \mathrm{CN}$ ) may be produced at low temperature (i.e. $\sim 40 \mathrm{~K}$ ) from ices containing formaldehyde and ammonia ${ }^{23,24}$.

Previous mechanistic studies of the Strecker reaction using quantum chemical calculations have been devoted to step (a) in the case $\mathrm{R}=\mathrm{H}^{25-31}$. Depending upon the theoretical level used, the computed critical energy for the formation of $\mathrm{H}_{2} \mathrm{NCH}_{2} \mathrm{OH}$ was situated between 115 $\mathrm{kJ} \cdot \mathrm{mol}^{-1}$ and $200 \mathrm{~kJ} \cdot \mathrm{mol}^{-1}$ with respect to the reactants $\mathrm{CH}_{2} \mathrm{O}+\mathrm{NH}_{3}$. The second step (b) has been predicted by theory to be more endothermic than step (a) by ca. 40-60 kJ.mol ${ }^{-1}{ }^{27,29,30}$ Consideration of a water solvent environment has been made by means of the isodensity surface polarizable model, IPCM, but without optimization of the geometry at this level, and inclusion of one or two discrete water molecules ${ }^{26,28}$ or a 6 water ice $\operatorname{model}^{30}$ and clusters 
including 4,9 or 12 water molecules ${ }^{31}$. In parallel, the reactivity of methaneimine with hydrogen cyanide (step (c), Scheme 1) has been studied both in vacuum and in aqueous solution $^{32,33}$ or in ice environment ${ }^{30}$.

After consideration of these previous results, it appears that (i) only a limited number of structures have been investigated so far and that (ii) the level of theory used was not necessarily sufficient to describe accurately the energetic aspects of these reactions. As a consequence, we propose here a large investigation at a uniform and high level of theory, including optimization of the geometries in the solvent environment, in order to offer a realistic view of the considered systems. For this purpose, we examine here the first steps (a) and (b) $(\mathrm{A} \rightarrow \mathrm{B} \rightarrow \mathrm{C}$, Scheme 1) of the Strecker synthesis of glycine $(\mathrm{R}=\mathrm{H}$, Scheme 1) by quantum chemical calculations, using the accurate composite methods $\mathrm{G} 3 \mathrm{~B} 3^{34}$. Starting from reactions between isolated species $\mathrm{CH}_{2}=\mathrm{O}$ and $\mathrm{NH}_{3}$ in the gas phase, we progressively examine the modifications brought by including explicitly several molecules of water acting as active catalysis and, further, a polarizable medium to mimic the bulk solvent or ice effects. Extensive explorations of the conformational spaces were done using methods which combine stationary and dynamic approaches developed in our group ${ }^{50,35}$. Activation of the reactants by protonation both in the gas-phase and in aqueous media is also considered. Conclusions as to whether the Strecker synthesis is a possible pathway leading to the primitive aminoacids are drawn.

\section{COMPUTATIONAL METHODS}

In order to construct the various potential energy profiles presented in this work, geometries of the central structures B, i.e. $\left(\mathrm{HOCH}_{2} \mathrm{NH}_{2}\right)\left(\mathrm{H}_{2} \mathrm{O}\right)_{\mathrm{n}}$ and $\left(\mathrm{HOCH}_{2} \mathrm{NH}_{3}{ }^{+}\right)\left(\mathrm{H}_{2} \mathrm{O}\right)_{\mathrm{n}}$ $(\mathrm{n}=0,1,2,3$ and 4$)$, were first generated. For low $\mathrm{n}$ values, i.e. from 0 to 2 , structures $\mathbf{B}$ have been built manually, by identifying hydrogen bond acceptor and donor sites able to fix $\mathrm{H}_{2} \mathrm{O}$ molecules. If chemical intuition may be sufficient to explore exhaustively the conformational landscapes of structures $\mathbf{B}$, it is not the case for the higher $n$ values where molecular dynamic (MD) simulation is necessary. For these last cases only $(n>2)$, we used the methodology combining the hierarchical approach and the Darwin's family tree building ${ }^{51}$. Indeed, this methodology has already been used successfully to study the microhydration of protonated $\mathrm{Na}$-acetylhistidine ${ }^{35}$. For the hierarchical approach, we used the Tinker molecular modeling package $^{36}$ associated with the AMOEBA ${ }^{37,38}$ polarizable force field. The parameters of the neutral $\mathrm{CH}_{2} \mathrm{NH}_{2}$ and $\mathrm{CH}_{2} \mathrm{OH}$ termination of ethylamine and ethanol allowed us to adjust the parameters of $\mathrm{HOCH}_{2} \mathrm{NH}_{2}$, respectively. In parallel, the parameters of $\mathrm{HOCH}_{2} \mathrm{NH}_{3}{ }^{+}$were adjusted on the basis of those of the $\mathrm{CH}_{2} \mathrm{NH}_{3}{ }^{+}$and $\mathrm{CH}_{2} \mathrm{OH}$ terminations of protonated glycine and serine, respectively. For a given starting structure, MD calculations were performed at 150 and $250 \mathrm{~K}$, and overall dynamic times of $1.6,16$ and 40 ps during which snapshots are extracted every $0.016,0.16$ and $0.4 \mathrm{ps}$, respectively. At this stage, we controlled that MD calculations with longer simulation times do not bring any new minima. Finally, this procedure led to several hundred of local minima. More precisely, 82 and 306 minima have been identified for $\left(\mathrm{HOCH}_{2} \mathrm{NH}_{2}\right)\left(\mathrm{H}_{2} \mathrm{O}\right)_{n}$ and 102 and 216 minima for $\left(\mathrm{HOCH}_{2} \mathrm{NH}_{3}{ }^{+}\right)\left(\mathrm{H}_{2} \mathrm{O}\right)_{n}$ 
with $\mathrm{n}=3$ and 4 , respectively. All these minima, with up to 4 explicit water molecules, were obtained from MD simulations which do not included any bulk water solvation effect.

All structures B obtained from calculations detailed above were optimized at the DFT level B3LYP using the double- $\zeta$ quality basis set $6-31 \mathrm{G}(\mathrm{d})$ and vibrational frequencies were calculated at the same DFT level to obtain enthalpies at $0 \mathrm{~K}$ and $298 \mathrm{~K}$ using the Gaussian09 suite of programs ${ }^{39}$. Among these local minima, those situated in the first ca. $20 \mathrm{~kJ} \mathrm{~mol}^{-1}$ potential energy range (B3LYP/6-31G(d) level) were retained in order to construct the potential energy profiles. At this stage, a Darwinian tree is built on all minima identified in order to control that each generation of conformations involving $n$ water molecule, $\mathrm{G}_{n}$, is related to the previous generation $\mathrm{G}_{n-1}$. Starting from the most stable structures $\mathbf{B}$, all reaction routes toward reactant $\mathbf{A}$ and products $\mathbf{C}$ were investigated and the corresponding transition and final structures identified. The search for the transition structures $\mathbf{B} \rightarrow \mathbf{A}$ and $\mathbf{B} \rightarrow \mathbf{C}$ has been also done at the B3LYP/6-31G(d) level and their connectivity to reactant and product systematically controlled by IRC calculations. Finally, energy computations have been accurately performed using the composite $\mathrm{G} 3 \mathrm{~B}^{34}$ method.

It may be recalled that, in the G3B3 procedure, the geometries of stable and transition structures are fully optimized with the hybrid functional B3LYP using the 6-31G(d) basis sets. The same level of theory is used to calculate harmonic frequencies in order (i) to obtain zero point energies and correction to enthalpies and, (ii) to calculate entropies in the rigidrotor harmonic oscillator approximation. Improved energies are then obtained by making use of several successive more elaborated computations taking into account larger basis sets (6$31+\mathrm{G}(\mathrm{d}), 6-31 \mathrm{G}(2 \mathrm{df}, \mathrm{p})$ and G3large) and larger electron correlation levels (MP2, MP4 and QCISD(T)). The final energy is calculated assuming additivity of the various contributions and including a higher-order correction (HLC) to remove the remaining deficiencies in the energy calculations. The G3B3 method has been assessed on a test set of 299 energies (enthalpies of formation, ionisation energies, electron affinities and proton affinities) ${ }^{34}$. The average absolute deviations from experiments of these 299 energies are less than $5 \mathrm{~kJ} \mathrm{~mol}^{-1}$. The precision on the enthalpy calculation reported in the present work is consequently expected to be close to this value. As a test control of this expectation we performed computations on the elementary components of the studied systems, namely neutral and protonated ammonia, water, formaldimine and formaldehyde, and on their monohydrated complexes. Standard heats of formations of these species as derived from G3B3 calculations agree with experiment within a standard deviation of $1.9 \mathrm{~kJ}^{-\mathrm{mol}^{-1}}$ (see Table 1 of the supplementary material).

The role of the solvent was also investigated by using the conductor-like polarizable continuum model (CPCM) ${ }^{40}$ at the G3B3 level. The corresponding energy contribution is the sum of an electrostatic component and a non-electrostatic term including cavitation dispersion and repulsion energies. In such calculations the choice of the size of the cavity is important, particularly for charged species. For the neutral systems, we adopted here the standard UFF cavity model wich places a sphere around each solute atom with the radii scaled by a factor 1.1. In the case of the protonated systems, we selected the United Atom topological model UAKS where atomic radii are optimised using the PBE0 (close to B3LYP) functional since it has been demonstrated to give the smallest mean absolute deviation with experiment for 
cationic species ${ }^{41}$. Indeed, we observed that the CPCM/UAKS $\Delta \mathrm{G}_{\text {solv,298 }}$ computed for $\mathrm{NH}_{4}{ }^{+}$ and $\mathrm{OH}^{-}$at the $\mathrm{G} 3 \mathrm{~B} 3$ level are equal to $-341 \mathrm{~kJ} \mathrm{~mol}^{-1}$ and $-431 \mathrm{~kJ} \mathrm{~mol}^{-1}$, respectively, in close agreement with the experimental values of $-356^{41}$ and $-438^{42} \mathrm{~kJ} \mathrm{~mol}^{-1}$. Ideally, in order to consider an ice environment, the knowledge of the corresponding dielectric constant $\varepsilon$ is necessary. However, it is highly probable that the "dirty" interstellar ices are of amorphous structure and thus do not pertain to a well defined crystalline system. Fortunately, the incidence of the precise value of $\varepsilon$ on the CPCM calculations is limited. For example, using $\varepsilon=78$, as for liquid water, or $\varepsilon=107$, as for ice $X I$, i.e. the most stable ice structure at low temperature, lead to solvation energies differing by less than $1 \mathrm{~kJ} \cdot \mathrm{mol}^{-1}$. The second important point to note is that the structures were systematically re-optimized at the B3LYP/6-31G(d) level in the aqueous environment. This leads to non-negligible improvement on the solvation energies, particularly for the larger ionized systems.

The $\Delta \mathrm{H}^{\circ}{ }_{0}, \Delta \mathrm{H}^{\circ}{ }_{298}$ and $\Delta \mathrm{G}^{\circ}{ }_{298}$ values are presented in Tables SI2-SI12 gathered in the Supporting Information. A summary of the most representative findings is presented on Figures 1-10 and Tables 1 and 2. Unless otherwise indicated, relative energies cited in the text are G3B3 calculated $0 \mathrm{~K}$ enthalpies differences expressed in $\mathrm{kJ} \cdot \mathrm{mol}^{-1}$, i.e. $\Delta \mathrm{H}_{0}^{\circ}=$ $\mathrm{H}_{0}^{\circ}$ (considered species) - $\mathrm{H}_{0}^{\circ}$ (most stable structure $\mathbf{A}$ ). We also denoted "critical energy" the differences $\mathrm{H}_{0}^{\circ}$ (transition structure) - $\mathrm{H}_{0}^{\circ}$ (starting species) and "stabilization energy" the difference $\mathrm{H}_{0}^{\circ}$ (considered complex) - $\mathrm{H}^{\circ}{ }_{0}$ ( separated components). Entropy is not discussed in the text, the reader may however find informations on this question in Tables SI2-SI12.

\section{RESULTS AND DISCUSSION}

Main results of the present study have been presented under two main sections. In the first one are gathered the results concerning the neutral systems $\left(\mathrm{CH}_{2} \mathrm{O}+\mathrm{NH}_{3}\right)+\mathrm{nH}_{2} \mathrm{O} \rightarrow$ $\left(\mathrm{HNCH}_{2}+\mathrm{H}_{2} \mathrm{O}\right)+\mathrm{nH}_{2} \mathrm{O}$ (denoted NW0, NW1, NW2, NW3 and NW4, for $\mathrm{n}=0-4$ respectively). The possibility of a parallel pathway $\left(\mathrm{CH}_{2} \mathrm{O}+\mathrm{NH}_{3}\right)+\mathrm{nH}_{2} \mathrm{O} \rightarrow\left(\mathrm{H}_{2} \mathrm{NCH}_{2}{ }^{+}+\right.$ $\left.\mathrm{HO}^{-}\right)+\mathrm{nH}_{2} \mathrm{O}$ has been also examined. The second section is concerned with protonated reagents $\left(\mathrm{CH}_{2} \mathrm{O}+\mathrm{NH}_{4}{ }^{+}\right)+\mathrm{nH}_{2} \mathrm{O} \rightarrow\left(\mathrm{H}_{2} \mathrm{NCH}_{2}{ }^{+}+\mathrm{H}_{2} \mathrm{O}\right)+\mathrm{nH}_{2} \mathrm{O}$ (denoted PW0, PW1, PW2, PW3 and PW4, for $\mathrm{n}=0-4$ respectively). For all the considered systems, we choose to denote initial, intermediate and final structures by letters A, B, C, as sketched in Scheme 1, while related transition structures are denoted by the combinations of letters $\mathbf{A B}$ and $\mathbf{B C}$.

A single water molecule may facilitate a reaction by either passive or active catalytic effects. As illustrated by Scheme 2 for the aminomethanol formation in presence of one molecule of water (system NW1), three kinds of passive catalytic effect may be a priori distinguished where the water molecule plays the role of either a hydrogen bond donor (' passive acid catalysis") or a hydrogen bond acceptor ('passive base catalysis"). Water may also assist a hydrogen shift by "transport catalysis". Finally, and most importantly, direct participation of the water molecules, resulting in $\mathrm{O}-\mathrm{H}$ and $\mathrm{N}-\mathrm{H}$ bonds formation and dissociation, may be also envisaged ("active catalysis"). 

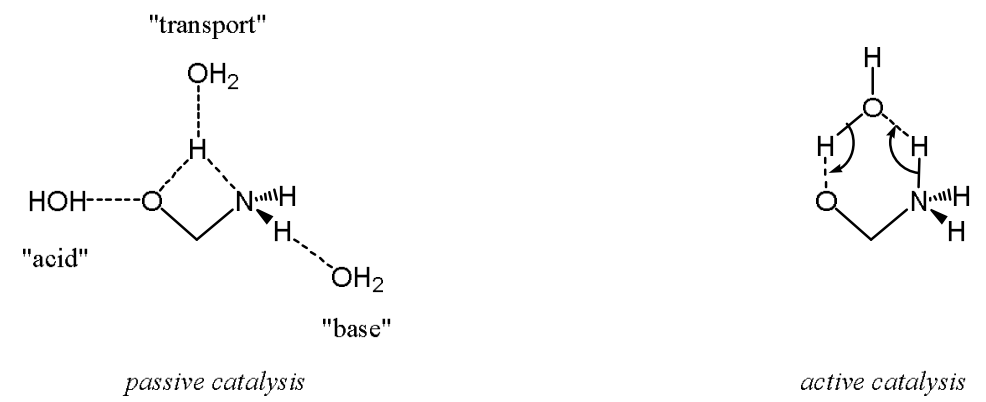

Scheme 2. "Passive" and "active" catalysis effect of a water molecule.

As expected and confirmed during the completion of the present work, "active" catalysis has a more pronounced effect than "passive" catalysis on the reaction energetic. To distinguish between these two categories of processes we decided to characterize the various reaction pathways by the notation $\mathbf{N}(\mathbf{P}) \mathbf{W}_{\mathbf{n}, \mathbf{x}}$ where $\mathbf{n}$ is the total number of discrete molecules of water and $x$ the number of which that are active. For example, the two possibilities of catalysis presented in Scheme 2 will be named $\mathbf{N W}_{\mathbf{3 , 0}}$ (left) and $\mathbf{N W}_{\mathbf{1 , 1}}$ (right) respectively.

\section{I. First step of the Strecker synthesis in neutral media}

NW0 system. Optimized B3LYP/6-31G(d) geometries of the various stable and transition structures involved along the reaction path summarized in Scheme 3 are dispatched in Figure 1 together with the corresponding $0 \mathrm{~K}$ enthalpy profile (detailed energetic data at 0 and $298 \mathrm{~K}$ are presented in Table SI2 of the Supporting Information).

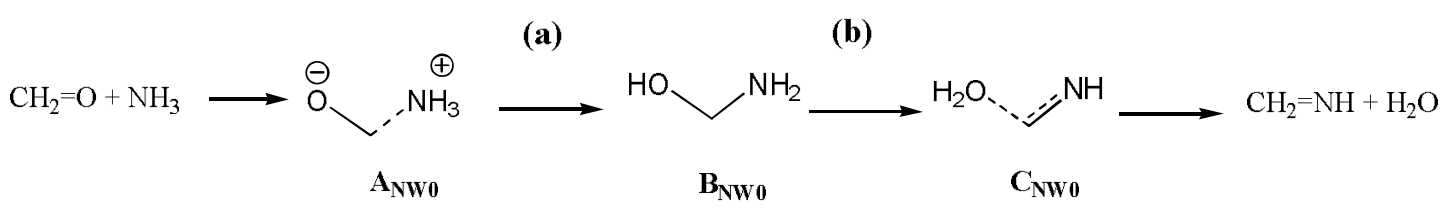

Scheme 3. The two first steps (a) and (b) of the Strecker synthesis in neutral media.

Approach of formaldehyde and ammonia may induce the formation of hydrogen bonded complexes or of a zwitterionic structure $\mathrm{NH}_{3}{ }^{+}-\mathrm{CH}_{2} \mathrm{O}^{-}, \mathrm{A}_{\mathrm{NW} 0}$ (Scheme 3). Calculation shows that this species is the more stable structure and that it may be more properly seen as a noncovalent complex between the two reactants. Accordingly, the distance between the carbon and the nitrogen atoms is too large $(2.763 \AA)$ to correspond to a covalent bond. The stabilization of this structure, by $7 \mathrm{~kJ} \cdot \mathrm{mol}^{-1}$, is essentially due to electrostatic attraction as corroborated by the fact that the nitrogen atom brings a negative charge ( -0.48 from Mulliken analysis) while the carbon atom presents a positive charge ( +0.19 from Mulliken analysis). 
Starting from $\mathbf{A}_{\mathrm{NW} 0}$, a 1,3-hydrogen migration from the amino group to the oxygen atom leads to the aminomethanol molecule $\mathrm{H}_{2} \mathrm{NCH}_{2} \mathrm{OH}$, in its conformation $\mathbf{B} 1_{\mathrm{NW}}$. The corresponding transition structure $\mathbf{A B}_{\mathrm{NW}}$, characterized by a negative wave number of -1578 $\mathrm{cm}^{-1}$, is situated $140 \mathrm{~kJ}^{\mathrm{mol}}{ }^{-1}$ above $\mathbf{A}_{\mathrm{NW} 0}$ (Figure 1) The second step of the reaction is a new 1,3-hydrogen migration from the nitrogen to the oxygen atoms. This reaction needs a prior rotation of the amino group which transforms $\mathbf{B} \mathbf{1}_{\mathrm{Nw}}$ into its conformer $\mathbf{B} \mathbf{2}_{\mathrm{NW}}$ before leading to the new species $\mathbf{C}_{\mathrm{Nwo}}$. This latter structure consists in a complex between methaneimine $\mathrm{CH}_{2}=\mathrm{NH}$ and a water molecule where one hydrogen bond is established between one $\mathrm{H}$ of the water molecule and the nitrogen atom of the incipient methyleneimine molecule $\left(\mathrm{H}^{\cdots} \mathrm{N}\right.$ distance $1.991 \AA$ ). This interaction probably brings the major part of the stabilization of this complex. Another favorable interaction should be noted however between one $\mathrm{H}$ of the methylene group and the oxygen atom $\left(\mathrm{H}^{\cdots} \mathrm{O}\right.$ distance $\left.2.635 \AA\right)$. The overall stability of complex $\mathbf{C}_{\mathrm{Nw}}$, i.e. the dissociation energy into its components, is equal to $16 \mathrm{~kJ} . \mathrm{mol}^{-1}$. The transition structure $\mathbf{B C}_{\mathrm{NW}}$, is characterized by an imaginary frequency of $-1909 \mathrm{~cm}^{-1}$, and is situated $206 \mathrm{~kJ} . \mathrm{mol}^{-1}$ above $\mathbf{A}_{\mathrm{Nw}}$. It represents the highest point of the energy profile presented in Figure 1.

Figure 1

The present G3B3 computational results are close to those obtained at the $\operatorname{CCSD}(\mathrm{T}) / \mathrm{cc}-$ pVDZ level by Walch et al. ${ }^{27}$ who, for example, calculate relative energies of 128 and 190 $\mathrm{kJ} . \mathrm{mol}^{-1}$ with respect to reactants for $\mathbf{A B}_{\mathrm{Nw}}$ and $\mathbf{B C}_{\mathrm{Nw} \mathbf{0}}$, respectively. Similarly, Woon ${ }^{26,31}$ places $\mathbf{A B}_{\text {Nwo }} 143 \mathrm{~kJ} \cdot \mathrm{mol}^{-1}$ above the complex $\mathbf{A}_{\mathrm{Nw}}$, in excellent agreement with our estimate of $140 \mathrm{~kJ} \cdot \mathrm{mol}^{-1}$. Finally, an excellent agreement is also found between our computation and the $\mathbf{B C}_{\mathrm{NW}}$ energy calculated by Feldmann et al. ${ }^{29}$ (within $2 \mathrm{~kJ} \cdot \mathrm{mol}^{-1}$ ) but, for an unidentified reason, these latter authors present result at variance from us (and also from Woon ${ }^{26,31}$ and $\mathrm{Walch}^{27}$ ) for the first step of the reaction since they place the transition structure $\mathbf{A B}_{\mathrm{NW}} 20 \mathrm{~kJ} \cdot \mathrm{mol}^{-1}$ higher. It must be emphasized that aminomethanol $\mathbf{B} \mathbf{2}_{\mathrm{NW}}$ is the local minimum of the system investigated; it lies $37 \mathrm{~kJ} \mathrm{~mol}^{-1}$ below the reactants and is 30 and $24 \mathrm{~kJ}_{\mathrm{mol}}{ }^{-1}$ more stable than complexes $\mathbf{A}_{\mathrm{NW} 0}$ and $\mathbf{C}_{\mathrm{NW}}$, respectively (Figure 1). Moreover, $\mathbf{B}_{\mathrm{NW}}$, is a thermochemically stable species protected over isomerization and dissociation by very large barriers. It is thus expected to be an observable molecule in the interstellar medium or in laboratory experiments if collisional stabilization freezes the molecule immediately after its formation.

Consideration of the solvent and ice lattice effects has been done using the CPCM continuum solvent model. Comparison of the vacuum and aqueous geometries is indicative of the changes induced by the solvent. For example, in the structure $\mathbf{A}_{\mathrm{NW}} \mathbf{0}$, the $\mathrm{C}^{\cdots} \mathrm{N}$ intermolecular distance is decreased by $0.085 \AA$ by the solvation. A comparable shortening of the hydrogen bond distance $\mathrm{OH}^{*} \mathrm{~N}$ is observed for the final complex $\mathbf{C}_{\mathrm{NW}}$. It is also noteworthy that the $\mathrm{OH}^{\cdots} \mathrm{N}$ angle in $\mathrm{C}_{\mathrm{Nw}}$ passes from 149 to $177^{\circ}$ upon solvation, thus replacing the internal $\mathrm{O}^{\cdots} \mathrm{HC}$ interaction by more favourable interactions with the solvent continuum. Concerning transition structures, the main point is the significantly more efficient 
solvation energies of $\mathbf{A B}_{\mathrm{NW}}$ thus reducing the barrier for aminoalcohol formation by $\sim 30$ $\mathrm{kJ} . \mathrm{mol}^{-1}$. By contrast the second step, $\mathbf{B} \rightarrow \mathbf{C}$, is essentially unaffected by the solvent.

It is clear from these results that, for the neutral system $\mathrm{CH}_{2} \mathrm{O}+\mathrm{NH}_{3}$, large activation barriers have to be surmounted to form methylenimine $\mathrm{HN}=\mathrm{CH}_{2}$. The process cannot be spontaneous unless large excitation energy (of ca. $200 \mathrm{~kJ} \mathrm{~mol}^{-1}$ ) is provided to the reactants.

NW1 system. Complexes $\left(\mathrm{CH}_{2} \mathrm{O}+\mathrm{NH}_{3}+\mathrm{H}_{2} \mathrm{O}\right) \mathbf{A}_{\mathrm{NW} 1}$ corresponding to the various catalytic possibilities of a water molecule depicted in Scheme 2 were investigated.

We present first the results obtained following the active catalytic route, NW1,1. The overall process $\left(\mathrm{CH}_{2} \mathrm{O}+\mathrm{NH}_{3}\right)+\mathrm{H}_{2} \mathrm{O} \rightarrow\left(\mathrm{HNCH}_{2}+\mathrm{H}_{2} \mathrm{O}\right)+\mathrm{H}_{2} \mathrm{O}$ summarized in Figure 2, involves the passage through two trimolecular complexes $\mathbf{A}_{N W 1,1}$ and $\mathbf{C}_{N w 1,1}$, and two bimolecular complexes $\mathbf{B} 1_{\mathrm{NW} 1,1}$ and $\mathbf{B} \mathbf{2}_{\mathrm{NW} 1,1}$.

Figure 2

The first structure, $\mathbf{A}_{\mathrm{NW1}, 1}$, looks like the zwitterionic species $\mathbf{A}_{\mathrm{NW}}$ described in the NW0 system, except however the internal solvation by one molecule of water. A comparison between $\mathbf{A}_{\mathrm{NW1} 1,}$ and $\mathbf{A}_{\mathrm{NW} 0}$ geometries reveals in the former a shorter $\mathrm{C}^{\cdots} \mathrm{N}$ distance $(2.539 \AA$ against $2.763 \AA$ in $\mathbf{A}_{\mathrm{Nw}}$ ). Several complexes between aminomethanol and a water molecule were identified. The structures directly involved in the active catalysis reaction mechanism, $\mathbf{B} 1_{\mathrm{NW1} 1,1}$ and $\mathbf{B} \mathbf{2}_{\mathrm{NW} 1,1}$, differ by the orientation of the amino group and thus by the nature of the intermolecular hydrogen bonds connecting aminomethanol and the water molecule. Cooperative hydrogen bonding networks $\mathrm{OH}^{\cdots} \mathrm{O}$ and $\mathrm{OH}^{\cdots} \mathrm{N}$ in one hand, and $\mathrm{O}{ }^{\cdots} \mathrm{HO}$ and $\mathrm{O} \cdots \mathrm{HN}$ in the other, operate in $\mathbf{B} 1_{\mathrm{NW} 1,1}$ and $\mathbf{B} \mathbf{2}_{\mathrm{NW} 1,1}$, respectively. The corresponding stabilization energies are essentially the same $\left(-59\right.$ and $-56 \mathrm{~kJ} \cdot \mathrm{mol}^{-1}$, respectively, with respect to the separated reactants). The most stable structure of complexes involving methylene imine and two molecules of water corresponds to the cyclic arrangement of the three molecules, $\mathbf{C}_{\mathrm{NW1}, 1}$, where three hydrogen bonds are cooperatively operating (Figure 2). By comparison with the lower homologue, a reinforcement of the hydrogen bonding is noted since the $\mathrm{OH}^{\cdots} \mathrm{N}$ distance is reduced by $0.12 \AA$ in $\mathbf{C}_{N W 1,1}$ with respect to $\mathbf{C}_{N W 0}$.

As seen from comparison of Figures 1 and 2, the relative energy levels of species $\mathbf{A}_{\mathrm{Nw}}$, $\mathbf{B}_{\mathrm{NW} 0}$ and $\mathbf{C}_{\mathrm{NW} 0}$ are comparable to that of $\mathbf{A}_{\mathrm{NW1} 1,1}, \mathbf{B} \mathbf{1}_{\mathrm{NW1}, 1}, \mathbf{B} \mathbf{2}_{\mathrm{NW1}, 1}$ and $\mathbf{C}_{\mathrm{NW1}, 1}$ : this obviously

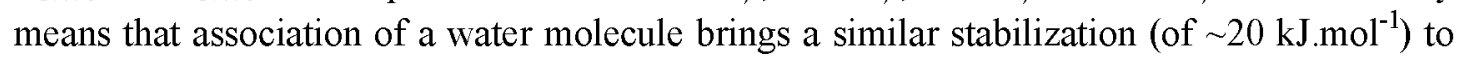
these species. The situation is clearly different for the two transition structures $\mathbf{A B}_{\mathrm{NW1,1}}$ and $\mathbf{B C}_{N w 1,1}$. Accordingly the critical energy of the first step $\mathbf{A}_{\mathrm{NW1}, 1} \rightarrow \mathbf{B} \mathbf{1}_{\mathrm{NW1}, 1}$ is equal to 63 $\mathrm{kJ} . \mathrm{mol}^{-1}$ while it was $140 \mathrm{~kJ}^{-\mathrm{mol}^{-1}}$ for the reaction occurring without water, $\mathbf{A}_{\mathrm{NW}} \rightarrow \mathbf{B} \mathbf{1}_{\mathrm{NWo}}$. This confirms the finding of Woon ${ }^{26,31}$ who find a dramatic decrease of ca. $75 \mathrm{~kJ} \mathrm{~mol}^{-1}$ of the corresponding critical energy by comparison with the pure unimolecular step (a). Similarly,

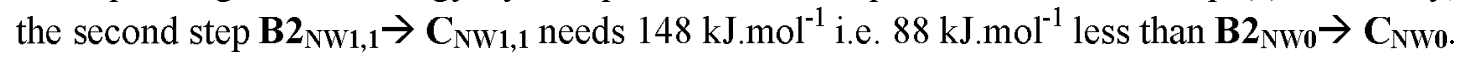
thus illustrating the expected catalytic effect of a single molecule of water. 
As observed for the NW0 system, CPCM calculations on the route NW1,1, essentially change the barrier for step (a) since the $\mathbf{A B}_{\mathrm{NW} 1,1}$ critical energy passes from 63 to $21 \mathrm{~kJ} \mathrm{~mol}^{-1}$ (Figure 2). The critical energy associated with step (b) is practically unchanged (from 148 to $140 \mathrm{~kJ} \cdot \mathrm{mol}^{-1} 1$ ).

The passive catalysis path $\mathbf{N W 1 , 0}$ has been examined by considering three starting points: "acid", "basic" and "transport" catalysis for both steps (a) and (b) (see Scheme 2 for step (a)). During this search we noted that all tentative of geometry optimisation of the corresponding transition structures converged on identical species which form the two highest points of the corresponding potential energy profile, $\mathbf{A B}_{\mathrm{Nw1,0}}$ and $\mathbf{B} \mathbf{C}_{\mathrm{Nw1,0}}$ indicated in Figure 2. As expected, the passive catalytic effect appears to be less efficient than the active catalysis NW1,1 presented above. Accordingly, the two transition structures $\mathbf{A B}_{\mathrm{NW1,0}}$ and $\mathbf{B C}_{\mathrm{NW1,0}}$ are situated 56 and $64 \mathrm{~kJ} \cdot \mathrm{mol}^{-1}$ above $\mathbf{A B}_{\mathrm{NW1} 1,1}$ and $\mathbf{B C}_{\mathrm{NW1}, 1}$, respectively (Figure 2). The corresponding critical energies, 119 and $212 \mathrm{~kJ} \cdot \mathrm{mol}^{-1}$, are however slightly less than that

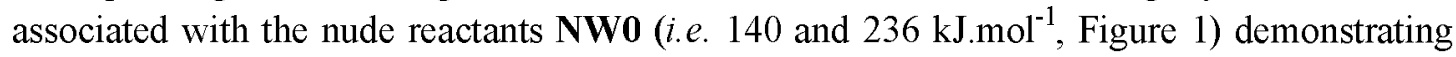
an effective, though limited, catalytic effect. Even if the CPCM calculation shows a significant stabilization of the transition structure $\mathbf{B C}_{\mathrm{NW1,0},}$, this is not enough to promote this reaction step.

In summary, as for the unsolvated system NW0, the energy determining step of the overall reaction NW1 is the formation of the imine, $\mathbf{B} \mathbf{2}_{\mathrm{NW} 1,1} \rightarrow \mathbf{C}_{\mathrm{NW} 1,1}$, and, even if the critical energy barrier is reduced by $90 \mathrm{~kJ}^{-\mathrm{mol}^{-1}}$ in the presence of one molecule of water, it still needs a significant activation of the reactants to proceed.

NW2 system. When combining formaldehyde with ammonia and two molecules of water, one may produce various complexes characterized by an elongated $\mathrm{C}^{\cdots \cdots} \mathrm{N}$ bond and cooperative network of hydrogen bonds. Some of them may result in the formation of solvated aminoalcohol via processes involving zero, one or two active molecules of water (NW2,0, NW2,1 or NW2,2 processes). Only the potential energy profile of the latter process is presented in Figures 3, the two other channels are illustrated by Figure SIl appearing in the Supporting Information part. A summary of the mechanistic aspects of the two reaction steps examined here is given in Scheme $4(\mathrm{n}=2)$.

The less energy demanding path is followed by the NW2,2 system where the two molecules of water play an active catalytic role (Scheme $4, n=2$, upper path). 

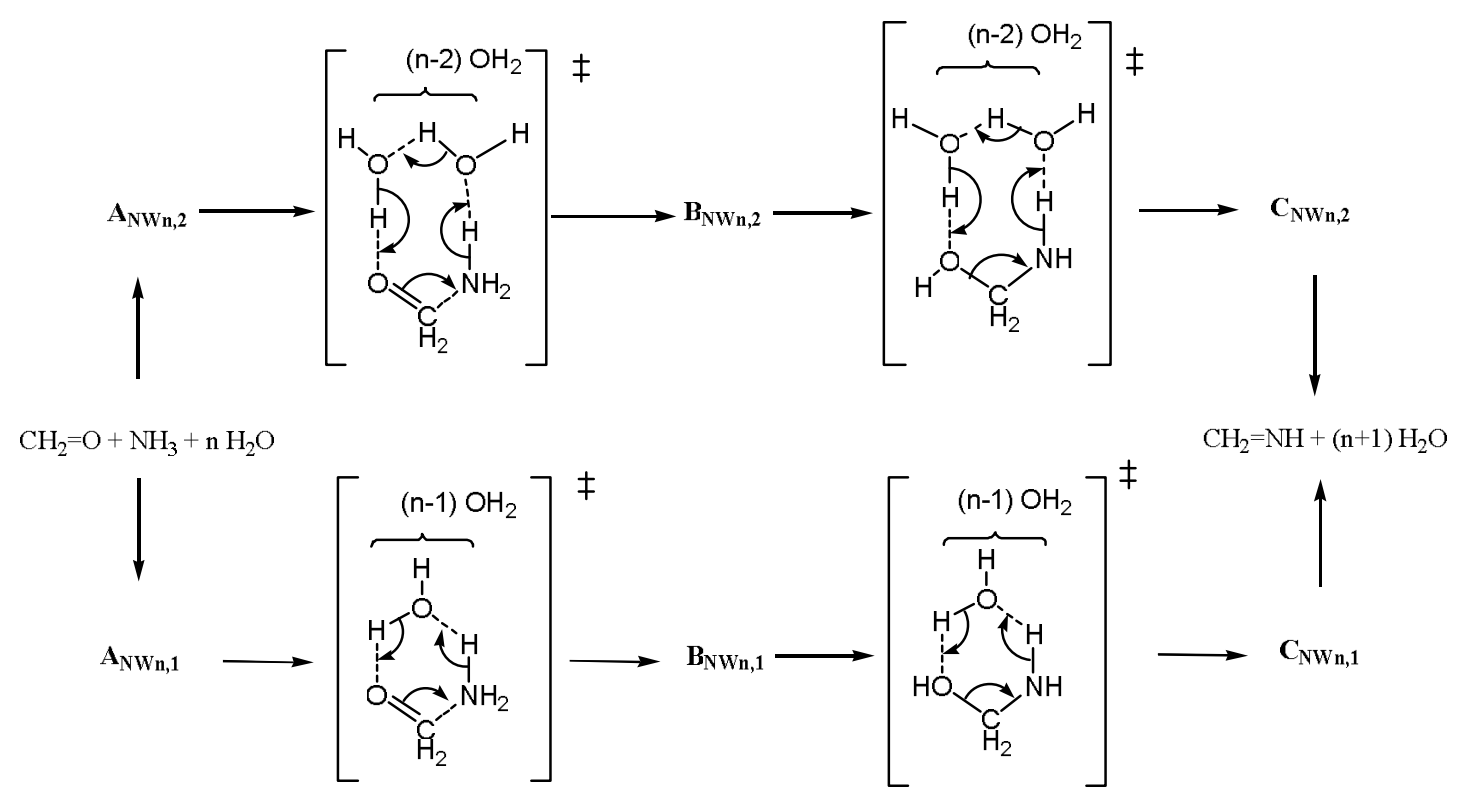

Scheme 4. Steps (a) and (b) of the active catalytic routes $\mathbf{N W n}, \mathbf{1}$ and $\mathbf{N W n}, \mathbf{2}(\mathrm{n}>2)$.

Figure 3

The starting complex, $\mathbf{A}_{\mathrm{NW} 2,2}$, exhibits a cooperative hydrogen bond network clumping together the two reactants and the two water molecules. It is interesting to note that the $\mathrm{OCH}_{2} \cdots \mathrm{NH}_{3}$ distance in $\mathbf{A}_{\mathrm{NW} 2,2}$ is equal to $2.37 \AA$, thus pointing to a shortening with respect to $\mathbf{A}_{\mathrm{NW0}}$ and $\mathbf{A}_{\mathrm{NW1} 1.1}$ A concerted process involving three hydrogen atoms and a $\mathrm{C}-\mathrm{N}$ bond formation leads to $\mathbf{B} 1_{\mathrm{NW} 2,2}$ (Figure 3). The critical energy for the step (a) $\mathbf{A}_{\mathrm{NW} 2,2} \rightarrow \mathbf{B} \mathbf{1}_{\mathrm{NW} 2,2}$ is equal to only $37 \mathrm{~kJ} \mathrm{~mol}^{-1}$, i.e. $26 \mathrm{~kJ} \mathrm{~mol}^{-1}$ less than the corresponding step in the system NW1,1. This catalytic effect due to the presence of the second molecule of water, is also significant, but to a lesser extent, for the second step (b): comparison of $\mathbf{B} \mathbf{2}_{\mathrm{NW} 1,1} \rightarrow \mathbf{C}_{\mathrm{NW} 1,1}$ and $\mathbf{B} 2_{\mathrm{NW} 2,2} \rightarrow \mathbf{C}_{\mathrm{NW} 2,2}$ shows a decrease of $24 \mathrm{~kJ} \mathrm{~mol}^{-1}$.

The aqueous environment as simulated by the CPCM model reduces once again the critical energies for steps (a) $\left(\mathbf{A}_{\mathrm{NW} 2,2} \rightarrow \mathbf{B} \mathbf{1}_{\mathrm{NW} 2,2}\right)$ and (b) $\left(\mathbf{B} \mathbf{N W}_{\mathrm{NW2}} \rightarrow \mathbf{C}_{\mathrm{NW} 2,2}\right)$ by 36 and $23 \mathrm{~kJ} \cdot \mathrm{mol}^{-1}$, respectively. Interestingly enough and as already noted by Chen and Woon ${ }^{31}$, the reaction $\mathbf{A}_{\mathrm{NW} 2,2} \rightarrow \mathbf{B} 1_{\mathrm{NW} 2,2}$ is predicted to be barrierless thus allowing the direct formation of the C-N bond in solvated aminomethanol $\mathbf{B} \mathbf{1}_{\mathrm{NW} 2,2}$.

The most favorable process involving only one active molecule of water, NW2,1, involves six membered ring structures solvated by one passive molecule of water (Scheme $5, \mathrm{n}=2$, bottom path). The reaction is analogous to that described above for the NW1,1 system but with one "external" water molecule. It is interesting to compare the corresponding energy profiles (Figure 2 for NW1,1 and Figure SI1 of the Supporting Information for NW2,1). Barriers for steps (b) are essentially the same $\left(\sim 145 \mathrm{~kJ} \mathrm{~mol}^{-1}\right)$ thus pointing to a negligible effect of the external molecule of water on this reaction. By contrast, the role of the "external" 
water molecule on the critical energy of step (a) is noticeable: $63 \mathrm{~kJ} \cdot \mathrm{mol}^{-1}$ for $\mathbf{A B}_{\mathrm{Nw1}}$ and 16 $\mathrm{kJ} . \mathrm{mol}^{-1}$ for $\mathbf{A B}_{\mathrm{NW} 2,1}$. Introducing the bulk solvent effect using the CPCM procedure does not change drastically the overall potential energy profile of this system (Fig SI1).

In summary, examination of the system NW2 shows that formation of the aminoalcohol intermediate (step (a) of the Strecker reaction) may occur via concerted reactions involving either six (one active molecule of water, NW2,1) or eight (two active molecules of water, NW2,2) membered transition structures. The most favorable mechanism, depicted in Scheme 4 and Figure 3, implies the active participation of two molecules of water. Moreover, the formation of aminomethanol is even predicted to be spontaneous if the solvent environment is considered using the CPCM procedure. Difficulties arise however when considering the second step (b) of this process. Accordingly, the transition structure $\mathbf{B C}_{\mathrm{NW2,2}}$ is situated 45 $\mathrm{kJ} . \mathrm{mol}^{-1}$ above the reactants and $91 \mathrm{~kJ} . \mathrm{mol}^{-1}$ above the stable complex $\mathbf{A}_{\mathrm{NW} 2,2}$ thus preventing any possible spontaneous formation of the imine $\mathrm{CH}_{2}=\mathrm{NH}$.

NW3 and NW4 systems. In the case of formaldehyde-ammonia system microsolvated by three and four molecules of waters, the most salient results are presented in Figure 4 and 5 . Additional results are also gathered in Figure SI2 and SI3 and Tables SI5 and SI6.

The two major low energy processes associated with steps (a) and (b) of the processes NW3 and NW4 are those where one or two molecules of water act as active catalysts (as summarized in Scheme 4 for $\mathbf{n}=3$ and 4 ). For both systems, and mainly for step (b), the most energetically favourable paths involve two active molecules of water (i.e. correspond to NW3,2 and NW4,2 processes). By comparison with the system NW2,2, it appears that introducing one or two more discrete spectator molecules of water doesn't change drastically the corresponding energy profiles (compare Figures 3,4 and 5). The corresponding decreases in critical energies are close to $10 \mathrm{~kJ} \cdot \mathrm{mol}^{-1}$ for step (a) and to $20 \mathrm{~kJ} \cdot \mathrm{mol}^{-1} \mathrm{l}$ for step (b). By contrast with the NW2,2 case, no spectacular effect of the bulk solvent is predicted by the CPCM calculation. In particular, the drastic lowering in critical energy observed for the step (a) of the $\mathbf{N W 2 , 2}$ route (from 37 to $1 \mathrm{~kJ} \mathrm{~mol}^{-1}$ ) is not reproduced for NW3,2 and NW4,2.

\section{Figure 4}

Figure 5

In conclusion to this part devoted to the neutral systems NWn $(n=0-4)$, a general comparison of the critical energies associated with steps (a) and (b) as a function of the number of molecules of water is proposed in Table 1.

Table 1. Calculated critical energies ${ }^{\mathrm{a}}\left(\mathrm{kJ}_{\mathrm{mol}}{ }^{1}\right)$ of the first steps of the Strecker's synthesis: neutral systems NWn.

\begin{tabular}{|c|c|c|c|c|}
\hline path & \multicolumn{2}{|c|}{ step (a) } & \multicolumn{2}{|c|}{ step (b) } \\
\hline$n, x^{b}$ & gas & bulk $^{\mathrm{c}}$ & gas & bulk \\
\hline
\end{tabular}




\begin{tabular}{|ccccc|}
\hline $\mathbf{0 , 0}$ & 140 & 106 & 236 & 232 \\
\hline $\mathbf{1 , 1}$ & 63 & 21 & 148 & 140 \\
$\mathbf{1 , 0}$ & - & 87 & 208 & 163 \\
\hline $\mathbf{2 , 2}$ & 37 & 1 & 129 & 111 \\
$\mathbf{2 , 1}$ & 16 & 19 & 144 & 133 \\
$\mathbf{2 , 0}$ & - & - & 248 & 236 \\
\hline $\mathbf{3 , 2}$ & 28 & 21 & 113 & 115 \\
$\mathbf{3 , 1}$ & 21 & 21 & 127 & 118 \\
$\mathbf{3 , 0}$ & - & - & 238 & 236 \\
\hline $\mathbf{4 , 3}$ & 42 & 50 & - & - \\
$\mathbf{4 , 2}$ & 25 & 20 & 102 & 92 \\
$\mathbf{4 , 1}$ & 14 & 15 & 123 & 117 \\
\hline
\end{tabular}

a) G3B3 calculated $\left[\mathrm{H}_{0}^{\circ}\right.$ (transition structure) - $\mathrm{H}_{0}^{\circ}$ (starting structure)] differences. b) $\mathrm{n}=$ total number of discrete molecules of water, $\mathrm{x}=$ number of active molecules of water. c) CPCM calculations.

Bringing together the data presented in this Table 1 and in Figures 1-5, it appears that the introduction of two molecules of water brings the major part of the structural and energetic change which may be induced by the solvation in aqueous media. If the decisive role of the first molecule of water clearly appears during step (a), this active participation of the water molecules is however not sufficient to overcome the highest transition structure of the overall reaction $\mathrm{CH}_{2}=\mathrm{O}+\mathrm{NH}_{3} \rightarrow \mathrm{CH}_{2}=\mathrm{NH}+\mathrm{H}_{2} \mathrm{O}$, namely the isomerization step (b).

In addition, one may note that the occurrence of a competitive dissociation path leading to the ionized species $\mathrm{OH}^{-}$and $\mathrm{CH}_{2} \mathrm{NH}_{2}{ }^{+}$should be excluded. Accordingly, the energies required for these processes to occur are higher than that presented above for the $\mathrm{CH}_{2}=\mathrm{O}+\mathrm{NH}_{3} \rightarrow$ $\mathrm{CH}_{2}=\mathrm{NH}+\mathrm{H}_{2} \mathrm{O}$ process by no less than $\sim 450 \mathrm{~kJ} \cdot \mathrm{mol}^{-1}$ in the gas phase and $\sim 70 \mathrm{~kJ}^{-\mathrm{mol}^{-1}}$ in solution (details of the calculations are presented in Figure SI8 and Table SI12).

\section{II. First step of the Strecker synthesis in acidic media}

For the sake of clarity, most of the details of the G3B3 calculations are presented in the Supporting Information part (Tables SI7 to SI11 for the $\mathrm{H}_{0}^{\circ}, \mathrm{H}_{298}^{\circ}$ and $\mathrm{G}_{298}^{\circ}$, Figure SI5 to SI7 for the chemical structures).

PW0 system. Thirty years ago, it has been predicted, on the basis of theoretical calculations, that $\mathrm{CH}_{2} \mathrm{O}$ and $\mathrm{NH}_{3}$ may react in the presence of a proton to generate several $\mathrm{CONH}_{6}{ }^{+}$ complexes $^{43}$. Three protons bound complexes of the form $\mathrm{CH}_{2} \mathrm{O} \cdots \mathrm{H}^{+\cdots} \mathrm{NH}_{3}$ and $\mathrm{CH}_{2} \mathrm{NH}^{\cdots} \mathrm{H}^{+\cdots} \mathrm{OH}_{2}$ together with two covalent structures ${ }^{+} \mathrm{H}_{3} \mathrm{NCH}_{2} \mathrm{OH}$ and $\mathrm{H}_{2} \mathrm{NCH}_{2} \mathrm{OH}_{2}{ }^{+}$ 
were predicted to be stable species in the gas phase. One year later, Terlouw and co-workers ${ }^{44}$ confirmed this proposal by identifying experimentally some of these complexes by mass spectrometry. The two covalent structures ${ }^{+} \mathrm{H}_{3} \mathrm{NCH}_{2} \mathrm{OH}$ and $\mathrm{H}_{2} \mathrm{NCH}_{2} \mathrm{OH}_{2}^{+}$are possible intermediates in the Strecker's like reaction channel connecting formaldehyde and methaneimine in presence of a proton as summarized in Scheme 6 (BPwo and $\mathbf{C}_{\text {Pwo, }}$ respectively).

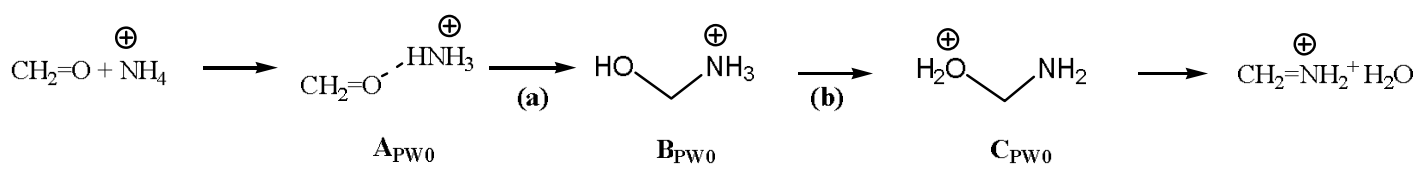

Scheme 5. The two steps (a) and (b) of he Strecker synthesis in acidic media.

Figure 6

Ammonia is by far more basic than formaldehyde (proton affinities of $\mathrm{NH}_{3}$ and $\mathrm{CH}_{2} \mathrm{O}$ are equal to 854 and $713{\mathrm{~kJ} . \mathrm{mol}^{-1} \text {, respectively) }}^{45}$ thus the most stable forms of the reactants are neutral formaldehyde and the protonated ammonia. Approach of these two entities leads to the proton bound complex A $A_{\text {Pwo }}$ which is stabilized by ca $80 \mathrm{~kJ} \cdot \mathrm{mol}^{-1}$ with respect to its components (Fig 6). It may be noted that this value is in perfect agreement with experimental $\mathrm{NH}_{4}^{+}$clustering energies reported earlier ${ }^{45-47}$. Passage from complex APwo to the Nprotonated aminomethanol, BPw0, involves a proton transfer from the nitrogen to the oxygen atoms and a concomitant formation of the C-N bond. This process, $\mathbf{A}_{\mathrm{PW} 0} \rightarrow \mathbf{B}_{\mathrm{PW},}$, passes through a transition structure $\mathbf{A B}_{\text {Pwo }}$ (Figure 6) where the $\mathrm{NH}_{3}$ moiety is almost at equal distance from the hydroxyl and the methylene groups $\left(\mathrm{d}\left(\mathrm{O}^{\cdots} \mathrm{N}\right)=2.96\right.$ and $\left.\mathrm{d}\left(\mathrm{C}^{\cdots \cdots} \mathrm{N}\right)=2.77 \AA\right)$. Formation of this transition structure needs approximately $150 \mathrm{~kJ}^{-\mathrm{mol}^{-1}}$ (Figure 6), a major part of which is due to the initial proton transfer (the proton transfer from ammonium cation to formaldehyde is associated with an endothermicity of $144 \mathrm{~kJ} . \mathrm{mol}^{-1}$ ).

The second step of the reaction is the tautomerization $\mathbf{B}_{\text {Pw0 }} \rightarrow \mathbf{C}_{\text {Pwo }}$ (step (b), Figure 6) which involves a 1,3 proton migration. The G3B3 calculated critical energy for this

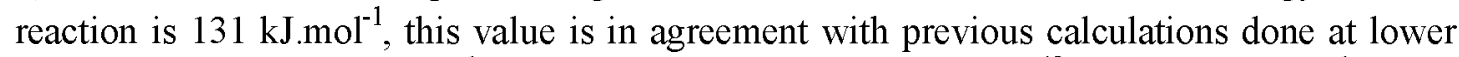
level of theory: $122 \mathrm{~kJ} \mathrm{~mol}^{-1}$ at the MP2/6-31G(d,p)+ZPE level ${ }^{48}$ and $144 \mathrm{~kJ}^{-\mathrm{mol}^{-1}}$ at the

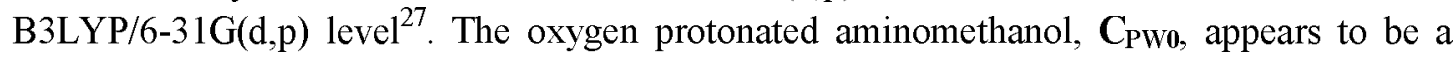
complex between the immonium cation and a water molecule since the distance between $\mathrm{O}$ and $\mathrm{C}(2.275 \AA)$ is by far larger than a covalent bond.

It appears clearly from Figure 6 that the reaction $\mathrm{CH}_{2} \mathrm{O}+\mathrm{NH}_{4}^{+} \rightarrow \mathrm{CH}_{2} \mathrm{NH}_{2}^{+}+\mathrm{OH}_{2}$ is not possible unless the reactants are activated by more than $70 \mathrm{~kJ} \cdot \mathrm{mol}^{-1}$. By contrast, formation of the $\mathrm{CH}_{2} \mathrm{NH}_{2}{ }^{+}+\mathrm{OH}_{2}$ products seems energetically possible from the couple of reactants $\mathrm{CH}_{2} \mathrm{OH}^{+}+\mathrm{NH}_{3}$. However, the proton transfer reaction $\mathrm{CH}_{2} \mathrm{OH}^{+}+\mathrm{NH}_{3} \rightarrow \mathrm{CH}_{2} \mathrm{O}+$ $\mathrm{NH}_{4}{ }^{+}$is expected to be more efficient due to its large exothermicity $\left(\Delta \mathrm{H}^{\circ}=144 \mathrm{~kJ} \cdot \mathrm{mol}^{-1}\right)$. This has been confirmed by experiments performed in an ion cyclotron resonance (ICR) mass spectrometer by allowing to react thermalized $\mathrm{CH}_{2} \mathrm{OH}^{+}$ions with $\mathrm{NH}_{3}$ under a pressure of $10^{-}$ 
${ }^{8} \mathrm{mbar}^{48}$. Accordingly, only the proton transfer reaction is observed. Moreover, deuterium labelling shows that the hydroxylic hydrogen is exclusively exchanged during the proton transfer reaction suggesting a direct mechanism $\mathrm{CH}_{2} \mathrm{OH}^{+}+\mathrm{NH}_{3} \rightarrow \mathrm{CH}_{2} \mathrm{O}+\mathrm{NH}_{4}^{+}$. This is confirmed by the fact that this reaction occurs close to its collision rate $\left(\sim 10^{-9} \mathrm{~cm}^{3} \cdot \mathrm{molec}^{-1} \cdot \mathrm{s}^{-}\right.$ $\left.{ }^{1}\right)^{49}$. Considering the dynamic range of the ICR instrument, the efficiency of the $\mathrm{CH}_{2} \mathrm{OH}^{+}+$ $\mathrm{NH}_{3} \rightarrow \mathrm{CH}_{2} \mathrm{NH}_{2}{ }^{+}+\mathrm{OH}_{2}$ reaction may be estimated to be less than $1 \%$ of the $\mathrm{CH}_{2} \mathrm{O}+\mathrm{NH}_{4}^{+}$ formation, this corresponds to a maximum value of the bimolecular rate constant of ca. $10^{-11}$ $\mathrm{cm}^{3} \cdot \mathrm{molec}^{-1} \cdot \mathrm{s}^{-1} \cdot{ }^{48}$

Taking into accounts the global solvent effect using the CPCM/UAKS methodology induces a significant effect on the stability of the protonated aminoalcohol intermediate $\mathbf{B}_{\mathrm{PW}}$ $\left(69 \mathrm{~kJ} \cdot \mathrm{mol}^{-1}\right)$ and, to a lesser extend, of the transition structure $\mathbf{B C}_{\mathrm{PW} 0}\left(38 \mathrm{~kJ} \cdot \mathrm{mol}^{-1}\right.$, Figure 6). The net result is an increase of the activation barrier of step (b).

PW1 system. Addition of one molecule of water to the system $\left[\mathrm{CH}_{2} \mathrm{O}+\mathrm{NH}_{4}{ }^{+}\right]$is expected to produce a large number of complexes stabilized by internal hydrogen bonds. In the framework of the present study, two possibilities were particularly interesting: structures $\mathbf{A}_{\mathrm{PW1}, 0}$ and $\mathbf{A}_{\mathrm{PW1} 1,}$ (Figure 7). The most stable structure, $\mathbf{A}_{\mathrm{PW1}, 0}$, corresponds to the situation where the ammonium cation stands in a central position, playing a double role of proton bond donor toward the oxygen atoms of the two basic molecules $\mathrm{CH}_{2} \mathrm{O}$ and $\mathrm{OH}_{2}$. In the second structure $\mathbf{A}_{\mathrm{PW1} 1,}$ (Figure 7), situated $14 \mathrm{~kJ} \mathrm{~mol}^{-1}$ above $\mathbf{A}_{\mathrm{PW1} \text {, }}$, the central position is occupied by the water molecule thus allowing formation of a network of cooperative hydrogen bonds between the three components.

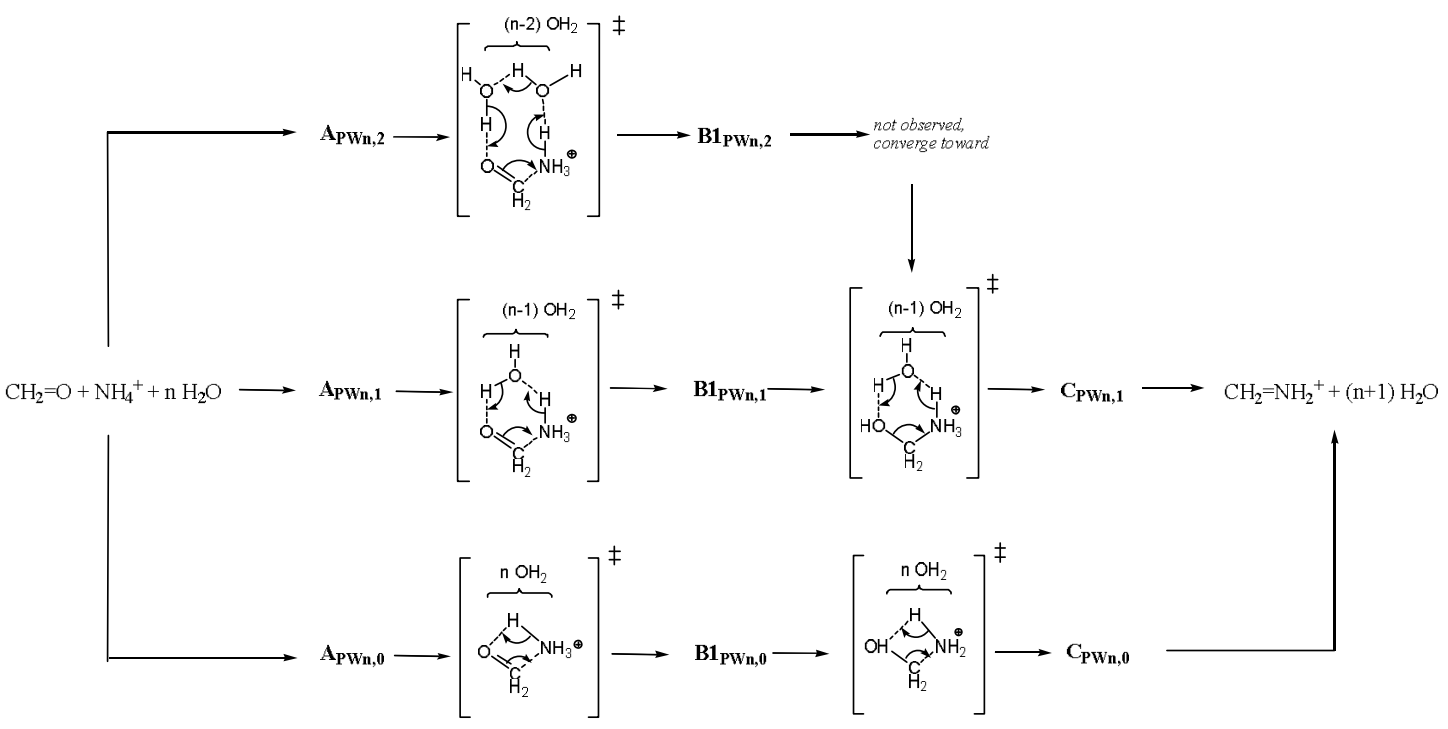

Scheme 6. Steps (a) and (b) of the catalytic routes PWn,0, PWn,1 and PWn, $2(n>2)$. 
Figure 7

Two reaction paths for the formation of the water solvated nitrogen protonated aminomethanol, $\mathbf{B}_{\mathrm{PW} 1}$, may be envisaged depending upon the initial formation of complexes $\mathbf{A}_{\mathrm{PW1,0}}$ or $\mathbf{A}_{\mathrm{Pw1,1}}$ (Scheme 6). It is noteworthy that structure $\mathbf{A}_{\mathrm{PW1}, 0}$ may be seen as structure

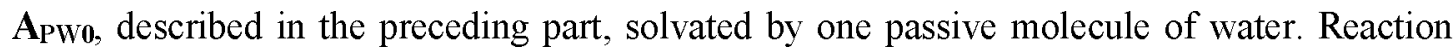
$\mathbf{A}_{\mathbf{P W 1}, 0} \rightarrow \mathbf{B}_{\mathbf{P W 1}, 0}$ is consequently similar to reaction $\mathbf{A}_{\mathbf{P W} 0} \rightarrow \mathbf{B}_{\mathbf{P W} 0}$, the added water molecule acting as a passive catalyst. Starting from $\mathbf{A}_{\mathbf{P W 1} 1,1}$ the situation is completely different since the added water molecule is situated between formaldehyde and the ammonium cation. It consequently can play an active part in the formation of $\mathbf{B}_{\mathrm{PW} 1,1}$ by bringing together the oxygen and nitrogen atoms through a six-membered transition structure. As expected, this latter route is energetically favoured over $\mathbf{A}_{\mathrm{PW} 1,0} \rightarrow \mathbf{B}_{\mathbf{P W 1}, \mathbf{0}}$. Accordingly, transition structure $\mathrm{AB}_{\mathrm{PW} 1,0}$ is situated $52 \mathrm{~kJ} \cdot \mathrm{mol}^{-1}$ above $\mathbf{A B}_{\mathrm{PW} 1,1}$ (Figure 7).

Structure $\mathbf{A}_{\mathrm{PW} 1,1}$ is more stable in a linear conformation in which the nitrogen and carbon atoms are far to each other. In order to produce structure $\mathbf{B}_{\mathbf{P W} 1,1}$, the reaction needs a migration of the $\mathrm{NH}_{3}$ group toward the carbon of the formaldehyde molecule and a proton exchange relayed by the water molecule. The corresponding transition structure, $\mathbf{A B}_{\mathbf{P W} 1,1}$ (Figure 7) shows clearly these geometrical constraints. After passing the transition structure $\mathbf{A B}_{\mathrm{PW1} 11}$ the system promptly relaxes to complex $\mathbf{B} 1_{\mathrm{PW1} 1,1}$. Rotation around the $\mathrm{CO}$ bond leads to complex $\mathbf{B} 2_{P W 1,1}$ which allows isomerization to $\mathbf{C}_{\mathrm{PW1} 1,1}$ by a concerted (cooperative) double hydrogen migration through $\mathbf{B C}_{\mathrm{PW1}, 1}$ (Figure 7). It may be noted that complex $\mathbf{C}_{\mathrm{PW1}, 1}$ is in fact a terbody structure which consists in an immonium ion solvated by two molecules of water.

If we compare the two systems PW0 and PW1, it appears that the role of the added molecule of water is to significantly decrease the critical energy of the step (b) of the reaction.

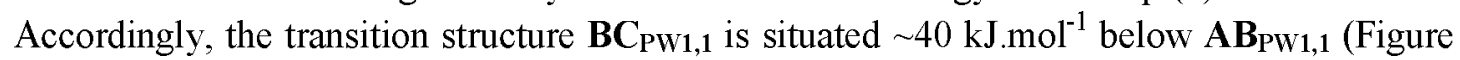
7), the difference was only $7 \mathrm{~kJ} \cdot \mathrm{mol}^{-1}$ between $\mathbf{A B}_{\mathrm{PW} 0}$ and $\mathbf{B C}_{\mathrm{PW0}}$ (Figure 6).

Once again, consideration of the global solvent effect by the CPCM/UAKS method induces a significant stabilisation of the protonated aminoalcohol $\mathbf{B}$ and of the transition structure BC. Indeed, $\mathbf{B} 1_{\mathrm{PW} 1,1}, \mathbf{B} 2_{\mathrm{PW} 1,1}$ and $\mathbf{B} \mathbf{C}_{\mathrm{PW} 1,1}$ are shifted downward by approximately $60 \mathrm{~kJ} \cdot \mathrm{mol}^{-1}$. Note that a comparable effect was also noted for $\mathbf{B}_{\mathrm{Pwo}}$. A stabilization of the transition structure $\mathbf{A B}_{\mathrm{PW} 1}$ of ca. $20 \mathrm{~kJ} . \mathrm{mol}^{-1}$ is observed here while, by comparison, no such effect was noted for $\mathbf{A B}_{\text {Pw0 }}$ (Figure 7).

PW2 system. Complexes formed by association of the reactants $\mathrm{CH}_{2} \mathrm{O}$ and $\mathrm{NH}_{4}^{+}$with two molecules of water may obviously present a large panel of structures. The most significant structures relevant to reactions involving zero, one or two active molecules of water and discussed in the lines below are presented in Figure SI4. The corresponding energy profiles are presented in Figure 8. 
Figure 8

As expected, the highest energy process corresponds to the $\mathbf{P W 2 , 0}$ route. The various stable and transition structures involved, starting from $\mathbf{A}_{\mathbf{P W 2 , 0}}$ to generate $\mathbf{C}_{\mathrm{PW}, \mathbf{2}, \text {, present clear }}$ analogies with their lower homologues $\mathbf{A}_{\mathbf{P w 1 , 0}}$ to $\mathbf{C}_{\mathrm{PW1,0}}$. A second observation is that the critical energies of the corresponding steps (a) and (b) are practically unchanged from PW1,0 (Figure 7) to PW2,0 (Figure 8). Apparently, the part played by the second passive molecule of water is negligible.

The lowest energy process corresponding to the active catalysis by one molecule of water starts with structure $\mathbf{A}_{\mathrm{PW} 2,1}$ which consists in its lower homologue $\mathbf{A}_{\mathrm{PW1}, 1}$ solvated by the second molecule of water. This latter establishes a hydrogen bond with the first molecule of water which creates a bridge between formaldehyde and the ammonium cation. Interestingly enough, this hydrogen bonding is preserved during the steps (a) and (b) of the reaction thus providing comparable stabilisation energy for each reaction intermediate. As a consequence, the potential energy profiles associated with reaction PW1,1 (Figure 7) and PW2,1 (Figure 8) are very similar.

Structure $\mathbf{A}_{\mathbf{P W 2} 2}$ consists in a linear arrangement of the type: $\mathrm{H}_{3} \mathrm{NH}^{+} \cdots \mathrm{OH}_{2} \cdots \mathrm{OH}_{2} \cdots \mathrm{O}=\mathrm{CH}_{2}$. This structure is slightly less stable than $\mathbf{A}_{\mathbf{P W}, 0}$ or $\mathbf{A}_{\mathbf{P W} 2,1}$ (presented in Figure SI4) but its cyclization is expected to favour the formation of the C-N bond through an eight-membered transition structure. Indeed, the process $\mathbf{A}_{\mathrm{PW} 2,2} \rightarrow \mathbf{B}_{\mathrm{PW} 2,2}$ is one of the two pathways (a) of lowest energy. Its transition structure is situated approximately at the same energy level as the $\mathbf{A}_{\mathbf{P W} 2,1} \rightarrow \mathbf{B}_{\mathbf{P W} 2,1}$ route (see Figure 8). It appears however that the pathway of lowest critical energy is $A_{P W 2,2} \rightarrow B_{P_{2}, 2}\left(82 \mathrm{~kJ} \mathrm{~mol}^{-1}\right.$, Figure 8). Concerning step (b) of the PW2,2 process, all our tentative converged toward $\mathbf{P W} \mathbf{2}, \mathbf{1}$ routes i.e. it seems impossible to imply two active molecules of water during the proton migration $\mathbf{B}_{\mathrm{PW} 2} \rightarrow \mathbf{C}_{\mathrm{PW} 2}$. Unavoidably, one molecule of water escapes the heart of the system to take a lateral position and play a passive catalytic role.

As already noted for the lower homologue systems, simulation of the solvent effect by the CPCM/UAKS procedure has a noticeable incidence on the stability of the intermediate structures $\mathbf{B}$ and on the transition structures $\mathbf{A B}_{\mathbf{P W 2 , 2}}$ and $\mathbf{B C}_{\mathbf{P W}, 1}$ leading to stabilization energies situated in the range $40-50 \mathrm{~kJ} . \mathrm{mol}^{-1}$ for both reaction steps.

PW3 and PW4 systems. Figures SI5 and SI6 contain views of the most important structures involved during the Strecker synthesis in acidic media (Scheme 6) in the presence of three and four molecules of water. The corresponding potential energy profiles are presented in Figures 9 (system PW3) and 10 (system PW4). For both systems establishment of a complete reaction path, including the two steps (a) and (b) of the Strecker reaction, has been possible only for the catalysis by one active molecule of water (paths PW3,1 and PW4,1). Only the step (a) has been identified for the paths PW3,2 and PW4,2 and the step (b) for the paths PW3,0 and PW4,0. From a mechanistic point of view, all these reaction paths correspond to the view sketched in Scheme 6. Passive solvation of the various species occurs between the oxygen of 
the added water molecules and the positively charged hydrogen atoms of the amino or hydroxyl groups.

Finally, a gain in stability of $40-60 \mathrm{~kJ} \cdot \mathrm{mol}^{-1}$ is again observed for aminoalocohols $\mathbf{B}$ and the corresponding transition structures $\mathrm{BC}$ on the path PW3,1 and PW4,1, by introducing the global solvent effect.

Figure 9

Figure 10

The main observations that emerge from this exploration of the Strecker reaction in acidic media are the following. Firstly, due to the presence of the positive charge, all noncovalent interactions become essential: the first approach complexes $A_{P W n}$ are stabilized by 80 to $270 \mathrm{~kJ}^{-m_{0}{ }^{-1}}$ with respect to their separated component. By comparison, this stabilization attains only 10 to $100 \mathrm{~kJ}_{\mathrm{mol}}{ }^{-1}$ for the neutral systems $\mathbf{A}_{\mathrm{NWn}}$. Secondly, the energy determining step in the protonated systems PWn is always step (a) while it was the step (b) for the neutral reactions NWn. Note however that the differences in critical energies between steps (a) and (b) in the protonated systems PWn rarely exceed $45 \mathrm{~kJ}^{\mathrm{mol}}{ }^{-1}$ (see Table 2 where a general comparison of the critical energies associated with processes $\mathbf{P W n}, \mathbf{0}$, $\mathbf{P W n}, \mathbf{1}$ and $\mathbf{P W n}, \mathbf{2}$ is presented); for the neutral system the corresponding difference was generally larger than $85 \mathrm{~kJ} \mathrm{~mol}^{-1}$ (Table 1). As also observed for the neutral systems, the fully passive catalysis routes $\mathbf{P W n}, \mathbf{0}$ have the highest critical energies. A comparison between the catalysis by one or two active molecules of water is only possible for the steps (a): in the three cases, the critical energies of the PWn,2 process is lower than that corresponding to the PWn, 1 route (Table 2).

Finally, taking into account the solvent effect by the CPCM/UAKS method does not change the preceding conclusions since the corresponding critical energies remains overall close to that calculated for the reactions occurring in the gas-phase (Table 2).

Table 2. Calculated critical energies ${ }^{\mathrm{a}}\left(\mathrm{kJ}_{\mathrm{mol}}{ }^{1}\right)$ of the first steps of the Strecker's synthesis: protonated systems PWn.

\begin{tabular}{|ccccc|}
\hline path & \multicolumn{2}{c}{ step (a) } & \multicolumn{2}{c|}{ step (b) } \\
\hline $\mathbf{n , \mathbf { x } ^ { \mathbf { b } }}$ & gas & bulk $^{\mathrm{c}}$ & gas & bulk $^{\mathrm{c}}$ \\
\hline $\mathbf{0 , 0}$ & 153 & 157 & 130 & 161 \\
\hline $\mathbf{1 , 1}$ & 106 & 98 & 70 & 83 \\
$\mathbf{1 , 0}$ & 172 & 158 & 116 & 144 \\
\hline $\mathbf{2 , 2}$ & 82 & 51 & - & - \\
$\mathbf{2 , 1}$ & 86 & 109 & 71 & 72 \\
\hline
\end{tabular}




\begin{tabular}{|ccccc|}
\hline $\mathbf{2 , 0}$ & 155 & 147 & 128 & 149 \\
\hline $\mathbf{3 , 2}$ & 111 & 61 & - & - \\
$\mathbf{3 , 1}$ & 155 & 120 & 84 & 85 \\
$\mathbf{3 , 0}$ & - & - & 146 & 165 \\
\hline $\mathbf{4 , 2}$ & 106 & 109 & - & - \\
$\mathbf{4 , 1}$ & 122 & 120 & 81 & 81 \\
$\mathbf{4 , 0}$ & - & - & 141 & 159 \\
\hline
\end{tabular}

a) $\mathrm{G} 3 \mathrm{~B} 3$ calculated $\left[\mathrm{H}_{0}^{\circ}\right.$ (transition structure) - $\mathrm{H}_{0}^{\circ}$ (starting structure)] differences. b) $\mathrm{n}=$ total number of discrete molecules of water, $x=$ number of active molecules of water. $c$ ) CPCM/UAKS calculations.

\section{III. The Strecker synthesis in interstellar- or astro-chemistry}

In the light of the present results, it appears that the two first steps of the Strecker synthesis are associated with a non negligible energy barrier, larger than or close to $\sim 100$ $\mathrm{kJ} \mathrm{mol}^{-1}$. The energy determining step is step (a), i.e. formation of the aminoalcohol, when the reaction occurs in presence of a proton, or, step (b) i.e. deshydration of aminoalcohol to produce the corresponding imine when the reaction occurs in neutral media. Obviously, passage over one of these energy barriers needs an activation of, either the reactant aldehyde plus ammonia, or the intermediate aminoalcohol. In the context of the Strecker reaction as a possible way to the first amino acids in prebiotic chemistry, such activation may be provided by various sources (absorption of electromagnetic radiation, impact of cosmic ray, collisions with high energy particles...), the extensive examination of which goes beyond the scope of the present study. We would like to underline here the possibility of chemical activation originating from the protonation process in the gas phase.

A first scenario, possible in the large timescale of prebiotic chemistry, would be a combination of step (a) in the neutral media (see the NW2,2 reaction in the bulk solvent which is practically barrierless, Table 1) and step (b) in a local protonated zone (PW2,1 is the less energy demanding process in the bulk solvent, but it still needs $70 \mathrm{~kJ}^{\mathrm{mol}}{ }^{-1}$, Table 2). A second possibility is to activate the reactant $\mathbf{A}$ by a prior intake of internal energy. From this point of view, it may be recalled that the initial protonation of one of the reactant in the gas phase may bring the required amount of internal energy if no deactivation by collision or radiation emission occur. In the interstellar media, the most abundant protonating agent is the $\mathrm{H}_{3}{ }^{+}$cation. Since the proton affinity of $\mathrm{H}_{2}$ is equal to $\mathrm{PA}\left(\mathrm{H}_{2}\right)=424 \mathrm{~kJ}_{\text {. }} \mathrm{mol}^{-1}{ }^{45}$, reaction of $\mathrm{H}_{3}{ }^{+}$ by proton transfer with a base $\mathrm{B}$ leads to products $\mathrm{BH}^{+}+\mathrm{H}_{2}$ containing an excess internal energy equal to $\mathrm{PA}(\mathrm{B})-424 \mathrm{~kJ} \cdot \mathrm{mol}^{-1}$. For example, protonation by $\mathrm{H}_{3}{ }^{+}$of small organic molecules such as $\mathrm{H}_{2} \mathrm{O}, \mathrm{H}_{2} \mathrm{CO}, \mathrm{NH}_{3}$, and $\mathrm{H}_{2} \mathrm{CNH}$ whose $\mathrm{PA}$ are equal to $691,713,854$ and $869 \mathrm{~kJ} \mathrm{~mol}^{-1}{ }^{45}$, respectively produce species containing internal energies situated between

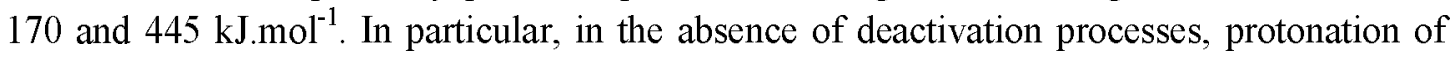
ammonia by $\mathrm{H}_{3}{ }^{+}$would bring $430 \mathrm{~kJ} \cdot \mathrm{mol}^{-1}$ internal energy of the products. This contribution is sufficiently high to promote the passage of steps (a) and (b) in acidic media as considered in 
the systems PWn. It is also possible to consider protonation of the intermediate structures $\mathbf{B}$ by the $\mathrm{H}_{3}{ }^{+}$cation after formation of the former in neutral phase, for example by the barrierless process NW2,2. The G3B3 calculated proton affinity of $\mathrm{H}_{2} \mathrm{NCH}_{2} \mathrm{OH}$ is equal to $883 \mathrm{~kJ}^{-\mathrm{mol}^{-1}}$ (this work). Protonation of this species by $\mathrm{H}_{3}^{+}$generates $\mathrm{H}_{3} \mathrm{NCH}_{2} \mathrm{OH}^{+}$cation containing at most $460 \mathrm{~kJ} \mathrm{~mol}^{-1}$, a quantity amply sufficient to allow the passage above the energy barrier associated to step (b) if the systems PWn.

\section{CONCLUSION}

Considering the whole results presented here on systems NWn and PWn, the Strecker synthesis of glycine seems unlikely to spontaneously occur in the gas phase or in aqueous solution without supplementary activation or catalysis. For the neutral reaction NWn the energy determining step (b) requires ca. 100-240 kJ.mol ${ }^{-1}$ in the gas-phase and in solution. Moreover, in all the studied neutral systems $(n=0-4)$, the transition structure for reaction step (b) is above that corresponding to step (a) (by at least $30 \mathrm{~kJ} \cdot \mathrm{mol}^{-1}$, Table 1 and Figures 1-5). Concerning the protonated systems PWn, a comparable situation is predicted but steps (a) and (b) play reversed roles. Indeed, the critical energies of step (a) are in the range $80-170 \mathrm{~kJ}^{-\mathrm{mol}^{-}}$ ${ }^{1}$ in the gas phase (50-160 $\mathrm{kJ}^{-\mathrm{mol}^{-1}}$ in aqueous media) and the corresponding transition structure is ca. $40{\mathrm{~kJ} . \mathrm{mol}^{-1}}^{-1}$ that of step (b) (Table 2 and Figures 6-10). One must conclude that the first steps of the Strecker synthesis have to face an energy barrier of $\sim 100 \mathrm{~kJ}^{\mathrm{mol}}{ }^{-1}$ in order to produce the imine $\mathrm{RCH}=\mathrm{NH}$, starting from the corresponding aldehyde $\mathrm{RCHO}$. 


\section{ASSOCIATED CONTENT}

Supporting Information. This file contains:

- calculated G3B3 (i) heats of formations (Table SI1) and (ii) relative and absolute enthalpies and free energies relevant to system (in the gas phase and in aqueous solution at 0 and $298 \mathrm{~K}$ ) (Tables SI2-SI12).

- Figures showing (i) potential energy profiles associated to systems NW2,0, NW2,1, NW3,0 and NW3,1 (Figures SI1-SI3, and (ii) structures relavant to the systems PW2, PW3, PW4 and $\mathrm{OH}\left(\mathrm{H}_{2} \mathrm{O}\right)_{\mathrm{n}}^{-}(\mathrm{n}=2-4)$ clusters (Figures SI4-SI7).

\section{NOTE}

This work was presented in part at the Colloque National d'Exobiologie, Orléans, France, 2224 March 2006.

\section{ACKNOWLEDGMENTS}

The authors thank Dr. Robert Pascal (University of Montpellier, France) for fruitful discussions during the (long) preparation of the present work. S. Huang, (Nanyang Technological University, School of Chemical and Biomedical Engineering, Nanyang Crescent, Singapore 637658) and B. S. Inda (Department of Chemistry, Indian Institute of Technology, Kanpur, Uttar Pradesh, India) are greatly acknowledged for their participation to the computational exploration of several potential energy surface during their stay in the laboratory.

\section{REFERENCES}

(1) Strecker, A. Ueber die künstliche Bildung der Milchsäure und einen neuen, dem glycocoll homologen. Ann. Chem. Pharm. 1850, 75, 27-45.

(2) Moutou, G.; Taillades, J.; Benefice-Malouet, S.; Commeyras, A. ; Messina, G.; Mansan R. Equilibrium of $\alpha$-aminoacetonitrile formation from formaldehyde, hydrogen cyanide and ammonia in aqueous solution: Industrial and prebiotic significance. J. Phys. Org. Chem. 1995, $8,721-730$.

(3) Groger, H. Catalytic Enantioselective Strecker Reactions and Analogous Syntheses. Chem. Rev. 2003, 103, 2795-2828.

(4) Najera, C.; Sansano, J.M. Catalytic Asymmetric Synthesis of a-Amino Acids. Chem. Rev. 2007, 107, 4584-4671.

(5) Wang, J.; Liu, X.; Feng, X. Asymmetric Strecker Reactions. Chem. Rev. 2011, 111, 69476983.

(6) Taillades, J.; Beuzelin, I.; Garrel, L.; Tabacik, V.; Bied, C.; Commeyras, A. N-Carbamoyl$\alpha$-Amino Acids Rather than Free $\alpha$-Amino Acids Formation in the Primitive Hydrosphere: A Novel Proposal for the Emergence of Prebiotic Peptides. Origins Life Evol. Biosphere 1998, 28, 61-77. 
(7) Miller, S. L. A Production of Amino Acids Under Possible Primitive Earth Conditions. Science 1953, 117, 528-529.

(8) Munoz Caro, G.; Meierhenrich, U.J.; Schutte, W.A.; Barbier, B.; Arcones Segovie, A.; Rosenbauer, H.; Thiemann, W.H-P.; Brack, A.; Greenberg, J.M. Amino acids from ultraviolet irradiation of interstellar ice analogues. Nature 2002, 416, 403-406.

(9) Lerner, N. R.; Cooper, G. W. Iminodicarboxylic acids in the Murchison meteorite: evidence of Strecker reactions. Geochim. Cosmochim. Acta 2005, 69, 2901-2906.

(10) Pascal, R.,; Boiteau L.; Comeyras, A. From the Prebiotic Synthesis of $\alpha$-Amino Acids Towards a Primitive Translation Apparatus for the Synthesis of Peptides. Top. Curr. Chem. 2005, 259, 69-122.

(11) Brack, A. From Interstellar Amino Acids to Prebiotic Catalytic Peptides: A Review. Chem. \& Biodiversity 2007, 4, 665-679.

(12) Elsila, J.E.; Dworkin, J.P.; Bernstein, M.P.; Martin, M.P.; Sandford, S.A. Mechanisms of Amino Acid Formation in Interstellar Ice Analogs. Astrophys. J. 2007, 660, 911-918.

(13) Lambert, J.F. Adsorption and Polymerization of Amino Acids on Mineral Surfaces: A Review. Orig. Life Evol. Biosph. 2008, 38, 211-242.

(14) Nuevo, M.; Auger, G.; Blanot, D.;D'Hendecourt, L. A Detailed Study of the Amino Acids Produced from the Vacuum UV Irradiation of Interstellar Ice Analogs. Orig. Life Evol. Biosph. 2008, 38, 37-56.

(15) Zaia, D.A.M.; Zaia, C.T.B.V.; De Santana, H. Which Amino Acids Should Be Used in Prebiotic Chemistry Studies? Orig. Life Evol. Biosph. 2008, 38, 469-488.

(16) Parker, E.T.; Cleaves II H.J.; Callahan, M.P.; Dworkin, J.P.; Glavin, D.P.; Lazcano, A.; Bada, J.L. Enhanced Synthesis of Alkyl Amino Acids in Miller's $1958 \mathrm{H}_{2} \mathrm{~S}$ Experiment. Orig. Life Evol. Biosph. 2011, 41, 569-574.

(17) Danger, G.; Plasson, R.; Pascal, R. Pathways for the formation and evolution of peptides in prebiotic environments. Chem. Soc. Rev. 2012, 41, 5416-5429.

(18) Burton, A.S.; Stern, J.C.; Elsila, J.E.; Glavin, D.P.; Dworkin, J.P. Understanding prebiotic chemistry through the analysis of extraterrestrial amino acids and nucleobases in meteorites. Chem. Soc. Rev. 2012, 41, 5459-5472.

(19) Ruiz-Mirazo, K.; Briones, C.; de la Escosura, A. Prebiotic Systems Chemistry: New Perspectives for the Origins of Life. Chem. Rev. 2014, 114, 285-366.

(20) Thaddeus, P. The prebiotic molecules observed in the interstellar gas. Philos. Trans. $R$. Soc. London, Ser. B 2006, 361, 1681-1687.

(21) Cleaves, II, H.J. The prebiotic geochemistry of formaldehyde. Precambrian Res. 2008, 164, 111-118.

(22) Pizzarello, S. The Chemistry of Life's Origin: A Carbonaceous Meteorite Perspective. Acc. Chem. Res. 2006, 39, 231-237.

(23) Bossa, J.B.; Theule, P.; Duvernay, F.; Chiavassa, T. $\mathrm{NH}_{2} \mathrm{CH}_{2} \mathrm{OH}$ thermal formation in interstellar ices contribution to the 5-8 $\mu \mathrm{m}$ region toward embedded protostars Astrophys. $J$. 2009, 707, 1524-1532.

(24) Danger, G.; Duvernay, F.; Theulé, P.; Borget, F.; Chiavassa, T. Hydroxyacetonitrile $\left(\mathrm{HOCH}_{2} \mathrm{CN}\right)$ formation in astrophysical conditions. Competition with the aminomethanol, a glycine precursor Astrophys. J. 2012, 756, 11(9pp). 
(25) Minyaev, R.M.; Lepin, E.A. Gradient line reaction path of ammonia addition to formaldehyde. Mendeleeev Commun. 1997, 7, 189-191.

(26) Woon. D. E. Ab Initio Quantum Chemical Studies of Reactions in Astrophysical Ices. 1. Aminolysis, Hydrolysis, and Polymerization in $\mathrm{H}_{2} \mathrm{CO} / \mathrm{NH}_{3} / \mathrm{H}_{2} \mathrm{O}$ Ices Icarus 1999, 142 , 550-556.

(27) Walch, S.P.; Bauschlicher Jr, C. W.; Ricca, A.; Bake E. L. O. On the reaction $\mathrm{CH}_{2} \mathrm{NH}_{2}$ $+\mathrm{HCN} / \mathrm{HNC} \rightarrow \mathrm{NH}_{2} \mathrm{CH}_{2} \mathrm{CNH}^{+}$. Chem. Phys. Lett. 2001, 346, 267-273.

(28) Courmier, D.; Gardebien, F.; Minot, C.; StAmant, A. A computational study of the water-catalyzed formation of $\mathrm{NH}_{2} \mathrm{CH}_{2} \mathrm{OH}$. Chem. Phys. Lett. 2005, 405, 357-363.

(29) Feldmann, M. T.;Widicus, S. L.; Blake, G. A. ; Kent IV, D. R. ;Goddard III, W. A. Aminomethanol water elimination: Theoretical examination. J. Chem. Phys. 2005, 123 , 034304 .

(30) Rimola, A.; Sodupe, M.;Ugliengo, P. Deep-space glycine formation via Strecker-type reactions activated by ice-water dust mantles. A computational approach.

PhysChemChemPhys. 2010, 12, 5285-5294.

(31) Chen, L.; Woon, D. E. A Theoretical Investigation of the Plausibility of Reactions between Ammonia and Carbonyl Species (Formaldehyde, Acetaldehyde, and Acetone) in Interstellar Ice Analogs at Ultracold Temperatures. J. Phys. Chem. A 2011, 115, 5166-5183.

(32) Arnaud, R.; Adamo, C.; Cossi, M.; Milet, A.; Vallée, Y.; Barone V. Theoretical Study of the Addition of Hydrogen Cyanide to Methanimine in the Gas Phase and in Aqueous Solution. J. Am. Chem. Soc. 2000, 122, 324-330.

(33) Koch, D.M.; Toubin, C.; Peslherbe, G.H.; Hynes, J.T. A Theoretical Study of the Formation of the Aminoacetonitrile Precursor of Glycine on Icy Grain Mantles in the Interstellar Medium. J. Phys. Chem. C 2008, 112, 2972-2980.

(34) Baboul, A.G.; Curtiss, L.A.; Redfern, P.C.; Raghavachari, K. Gaussian-3 theory using density functional geometries and zero-point energies. J. Chem. Phys. 1999, 110, 7650.

(35) Riffet, V.; Bouchoux, G.; Frison, G. Microhydration of Protonated Na-Acetylhistidine: A Theoretical Approach. J. Phys. Chem. B 2015, 119, 11527-11539.

(36) Ponder, J.W. TINKER - Software Tools for Molecular Design, version 6.0, 2011.

(37) Ren, P.Y.; Ponder, J.W. Consistent treatment of inter- and intramolecular polarization in molecular mechanics calculations. J. Comput. Chem. 2002, 23, 1497-1506.

(38) Ponder, J. W.; Wu, C. J.; Ren, P. Y.; Pande, V. S.; Chodera, J. D.; Schnieders, M. J.; Haque, I.; Mobley, D. L.; Lambrecht, D. S.; DiStasio, R. A. Current Status of the AMOEBA Polarizable Force Field. J. Phys. Chem. B 2010, 114, 2549-2564.

(39) Frisch, M.J. ; G.W. Trucks, H.B. Schlegel, G.E. Scuseria, M.A. Robb, J.R. Cheeseman, G. Scalmani, V. Barone, B. Mennucci, G.A. Petersson et al, Gaussian, Inc., Wallingford CT, 2010. Gaussian 09, Revision B.01

(40) Barone, V. ; Cossi, M.; Tomasi J. A new definition of cavities for the computation of solvation free energies by the polarizable continuum model. J. Chem. Phys. 1997, 107, 3210.

(41) Takano, Y.; Houk, K.N. Benchmarking the Conductor-like Polarizable Continuum Model (CPCM) for Aqueous Solvation Free Energies of Neutral and Ionic Organic Molecules. J. Chem. Theory Comput. 2005, 1, 70-77. 
(42) Camaioni, D.M.; Schwerdtfeger, C.A. Comment on "Accurate Experimental Values for the Free Energies of Hydration of $\mathrm{H}^{+}, \mathrm{OH}^{-}$, and $\mathrm{H}_{3} \mathrm{O}^{+\prime}$. J. Phys. Chem. A 2005, 109, 10795 10797.

(43) Bouchoux, G; Hoppilliard Y. Stable covalent and hydrogen-bonded acid-base association. $\mathrm{Ab}$ initio study of $\left[\mathrm{CH}_{2} \mathrm{O} \cdot \mathrm{H} \cdot \mathrm{NH}_{3}\right]^{+}$and $\left[\mathrm{CH}_{2} \mathrm{NH} \cdot \mathrm{H} \cdot \mathrm{OH}_{2}\right]^{+}$complexes Int. J. Mass Spectrom. Ion Proc.1987, 75, 1-14.

(44) Heerma, W. ;Kulik, W. ;Burger, P.C.; Terlouw J.K. The ion-dipole complex $\left[\mathrm{CH}_{2} \mathrm{NH}_{2} / \mathrm{H}_{2} \mathrm{O}\right]^{+}$: Its generation as a stable species in the gas phase from protonated $\beta$-alanine. Int. J. Mass Spectrom.Ion Proc. 1988, 84, R1-R5

(45) Bouchoux, G. Gas-phase basicities of polyfunctional molecules. Part 1: Theory and methods. Mass Spectrom. Rev. 2007, 26, 775-835.

(46) Mautner, M.; Sieck, L.W.; Liebman J.F.; Scheiner S. Complexing of the Ammonium Ion by Polyethers. Comparative Complexing Thermochemistry of Ammonium, Hydronium, and Alkali Cations. J. Phys. Chem. 1996, 100, 6445-6450.

(47) Adams, N.G.; Babcock, L.M.; Mostefaoui, T.M.; Kerns M.S. Selected ion flow tube study of $\mathrm{NH}_{4}{ }^{+}$association and of product switching reactions with a series of organic molecules Int. J. Mass Spectrom. 2003, 223/224, 459-471.

(48) Uggerud, E. Nucleophilic addition/elimination on substituted methyl cations. Analysis of factors that affect thermochemistry and barrier heights.

J. Chem. Soc. Perkin 2, 1996, 1915-1920.

(49) Okada, S.; Abe, Y.; Taniguchi, S.; Yamabe S. Kinetic and theoretical study on the ion/molecule reactions of methoxymethyl cation with ammonia J. Am. Chem. Soc. 1987,109, 295-300.

(50) Jacquemin, D.; Michaux, C.; Perpète, E.A.; Frison, G. Comparison of Microhydration Methods: Protonated Glycine as a Working Example. J. Phys. Chem. B 2011, 115, 36043613 .

(51) Michaux, C; Wouters, J; Jacquemin, D; Perpete, E.A. A theoretical investigation of the hydrated glycine cation energetics and structures. Chem. Phys. Lett. 2007, 445, 57-61. 


\section{Figures Caption}

Figure 1. Zero Kelvin enthalpy profile for the NW0 system; dotted lines = CPCM calculations.

Figure 2. Zero Kelvin enthalpy profile for the NW1 system: (i) "active catalysis" by 1 water molecule (NW1,1), and (ii), no active catalysis but 1 water "spectator" molecule (NW1,0); dotted lines = CPCM calculations.

Figure 3. Zero Kelvin enthalpy profile for the NW2 system with "active catalysis" by 2 water molecules (NW2,2); dotted lines $=$ CPCM calculations.

Figure 4. Zero Kelvin enthalpy profile for the NW3 system with "active catalysis" by 2 water molecules plus 1 water "spectator" molecule (NW3,2); dotted lines = CPCM calculations.

Figure 5. Zero Kelvin enthalpy profile for the NW4 system with "active catalysis" by 2 water molecules plus 2 water "spectator" molecules (NW4,2); dotted lines = CPCM calculations.

Figure 6. Zero Kelvin enthalpy profile for the PW0 system; dotted lines = CPCM/UAKS calculations.

Figure 7. Zero Kelvin enthalpy profile for the PW1 system: (i) "active catalysis" by 1 water molecule (PW1,1), and (ii), no active catalysis but 1 water "spectator" molecule (PW1,0); dotted lines = CPCM/UAKS calculations.

Figure 8. Zero Kelvin enthalpy profile for the PW2 system: (i) no active catalysis but 2 water "spectator" molecules, (PW2,0), (ii) "active catalysis" by 1 water molecule plus 1 water "spectator" molecule, (PW2,1), (iii) "active catalysis" by 2 water molecules (PW2,2); dotted lines = $\mathrm{CPCM} / \mathrm{UAKS}$ calculations (for clarity, structures are presented separately in Figure SI4 of SI).

Figure 9. Zero Kelvin enthalpy profile for the PW3 system: (i) no active catalysis but 3 water "spectator" molecules (PW3,0), (ii) "active catalysis" by 1 water molecule plus 2 water "spectator" molecules ((PW3,1), (iii) "active catalysis" by 2 water molecules plus 1 water "spectator" molecule (PW3,2); dotted lines = CPCM/UAKS calculations (for clarity, structures are presented separately in Figure SI5 of SI).

Figure 10. Zero Kelvin enthalpy profile for the PW4 system: (i) no active catalysis but 4 water "spectator" molecules (PW4,0), (ii) "active catalysis" by 1 water molecule plus 3 water "spectator" molecules (PW4,1), (iii) "active catalysis" by 2 water molecules plus 2 water "spectator" molecules $(\mathbf{P W 4 , 2})$; dotted lines = CPCM/UAKS calculations (for clarity, structures are presented separately in Figure SI6 of SI). 


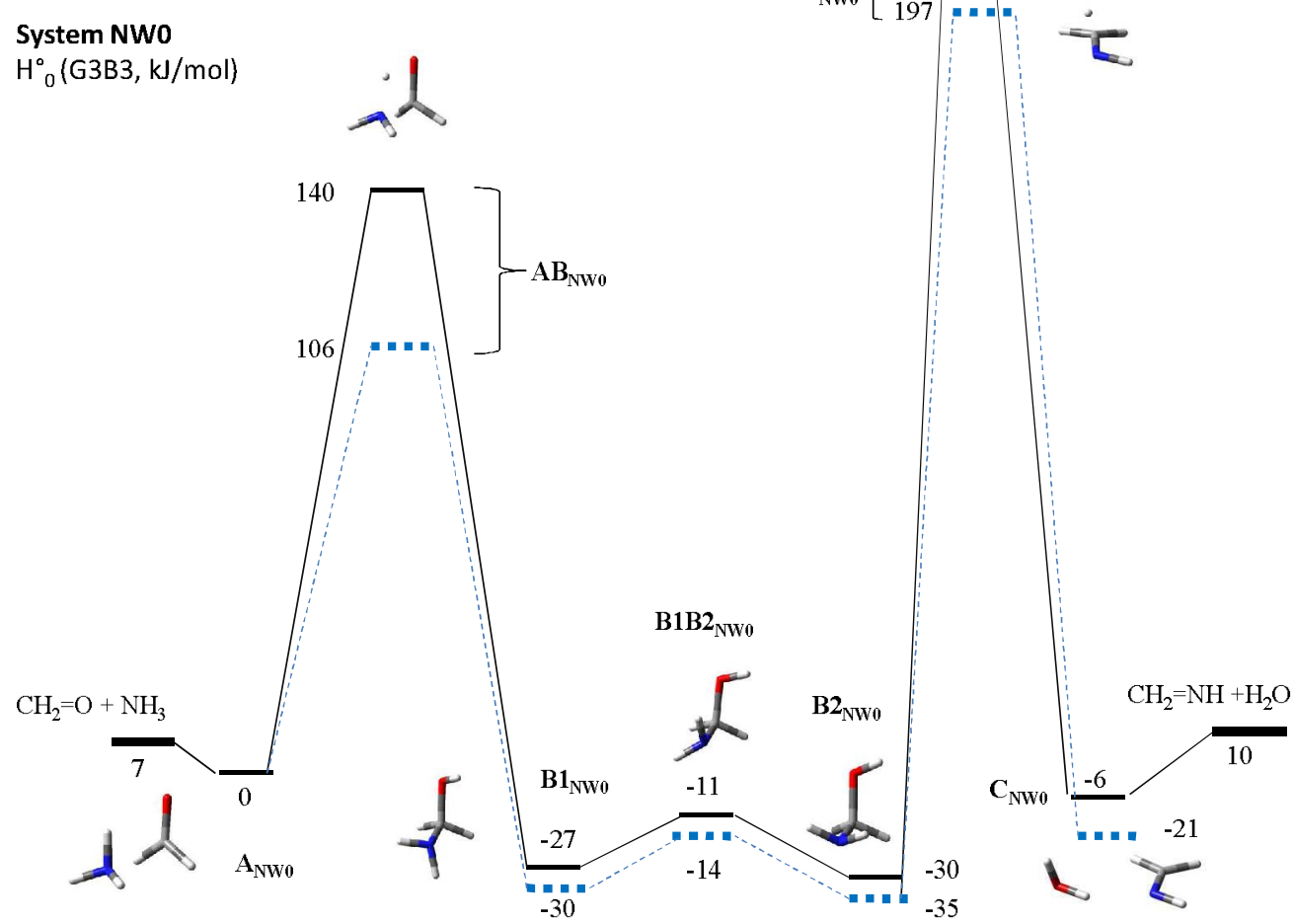

Figure 1. Zero Kelvin enthalpy profile for the NW0 system; dotted lines = CPCM calculations.

ACS Paragon Plus Environment 


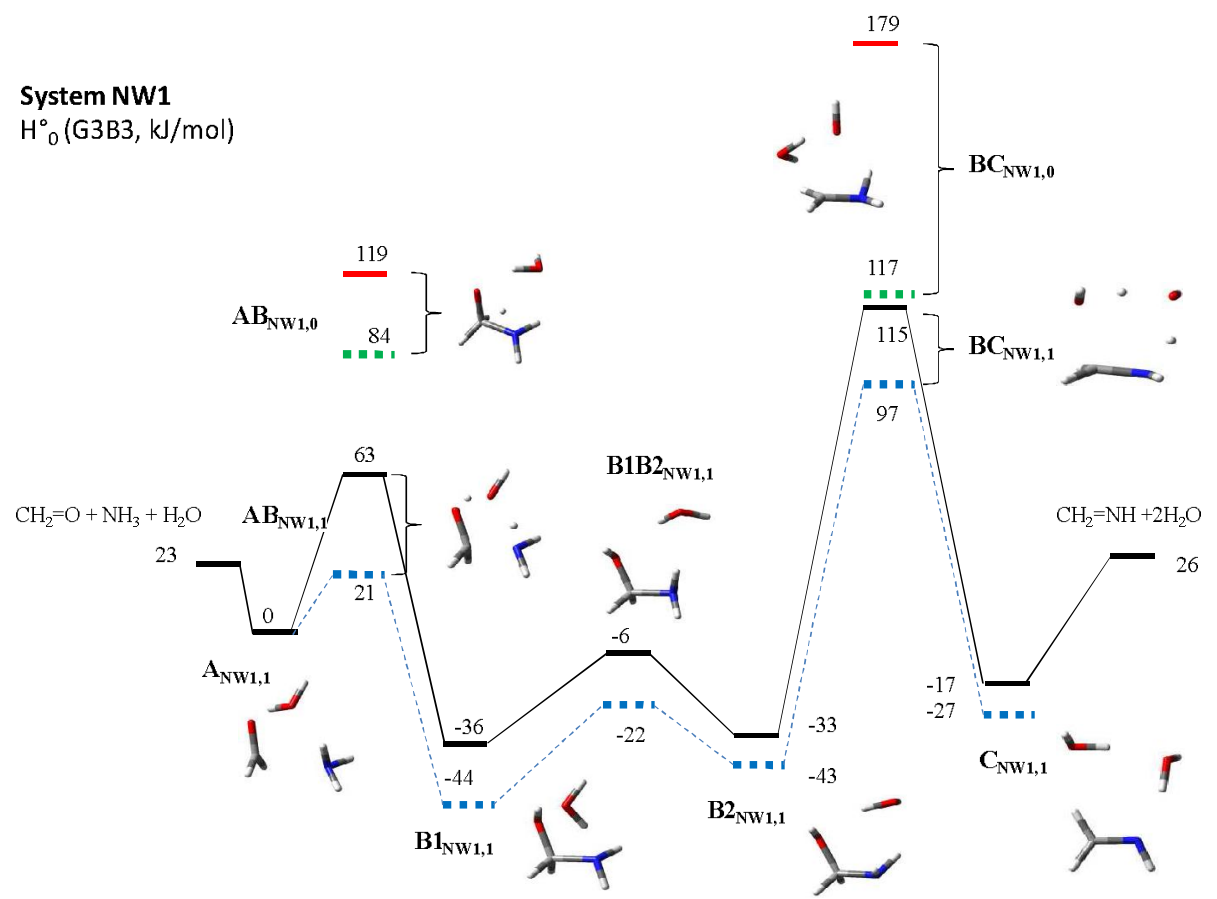

Figure 2. Zero Kelvin enthalpy profile for the NW1 system: (i) "active catalysis" by 1 water molecule (NW1,1), and (ii), no active catalysis but 1 water "spectator" molecule (NW1,0); dotted lines = CPCM calculations. 

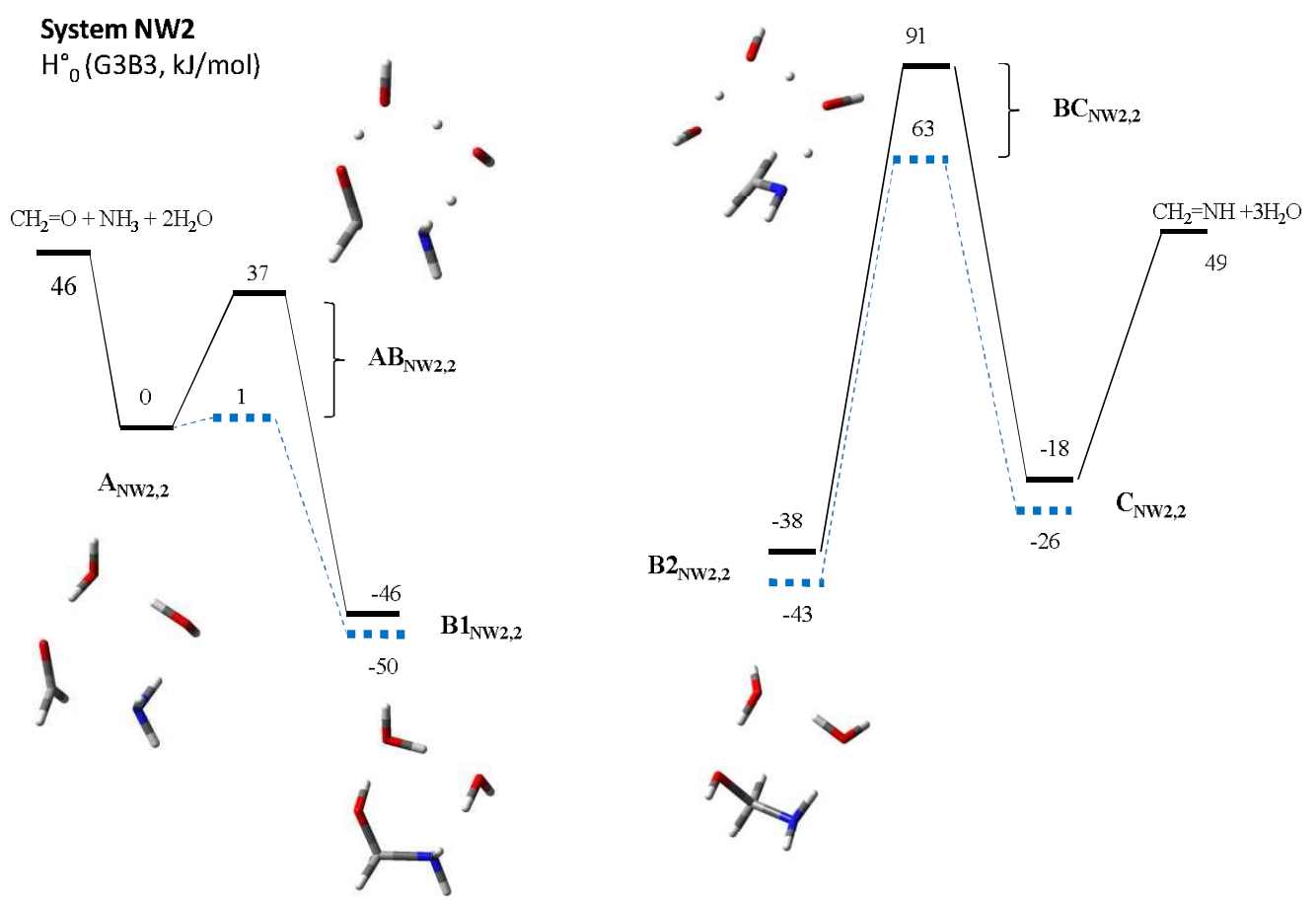

Figure 3. Zero Kelvin enthalpy profile for the NW2 system with "active catalysis" by 2 water molecules (NW2,2); dotted lines $=$ CPCM calculations.

ACS Paragon Plus Environment 
Modeling the First Step of the Strecker Synthesis
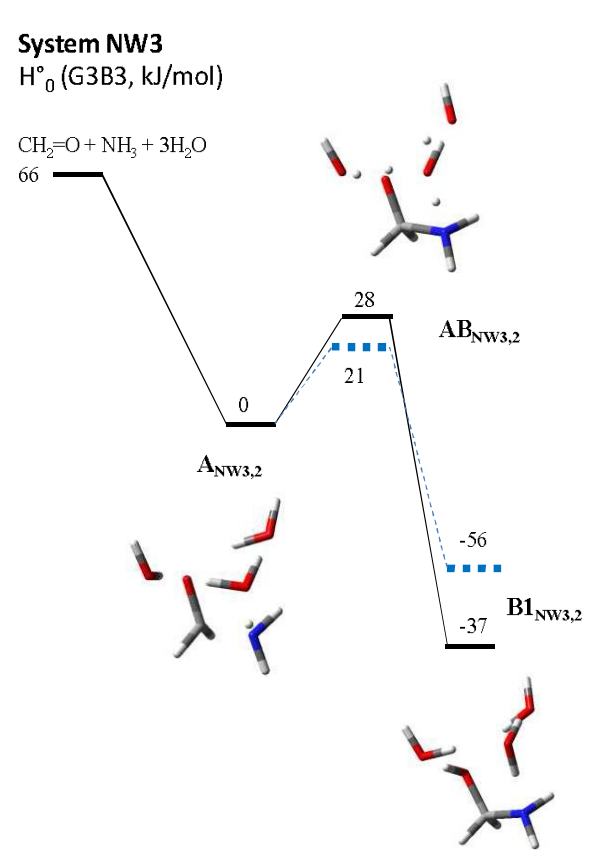

28

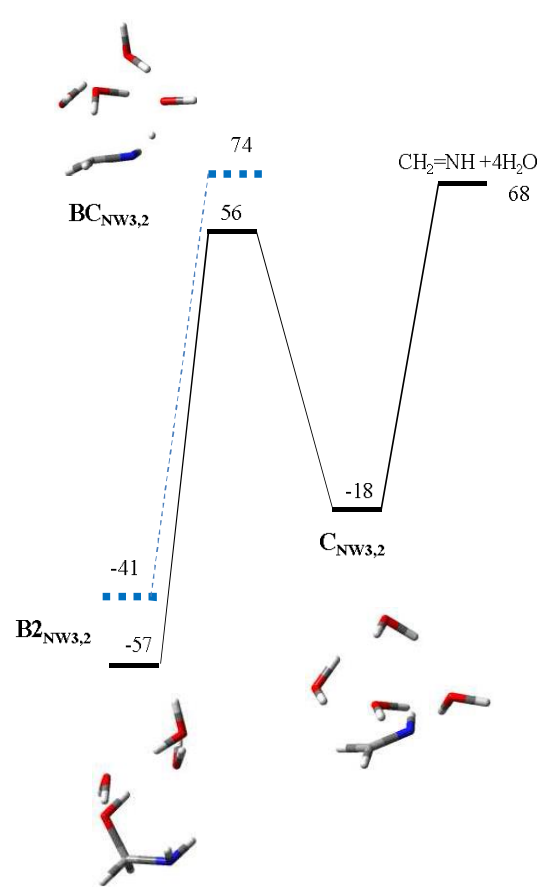

Figure 4. Zero Kelvin enthalpy profile for the NW3 system with "active catalysis" by 2 water molecules plus 1 water "spectator" molecule (NW3,2); dotted lines = CPCM calculations. 

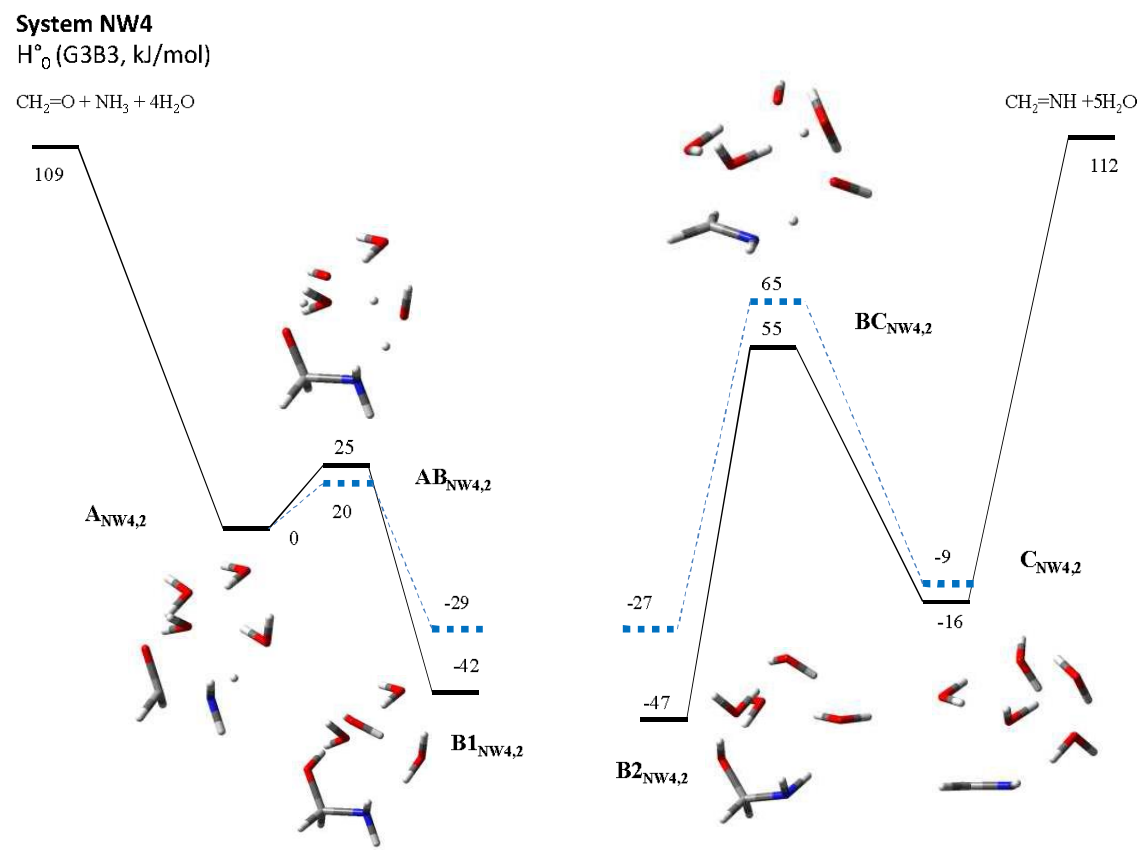

Figure 5. Zero Kelvin enthalpy profile for the NW4 system with "active catalysis" by 2 water molecules plus 2 water "spectator" molecules (NW4,2); dotted lines = CPCM calculations. 


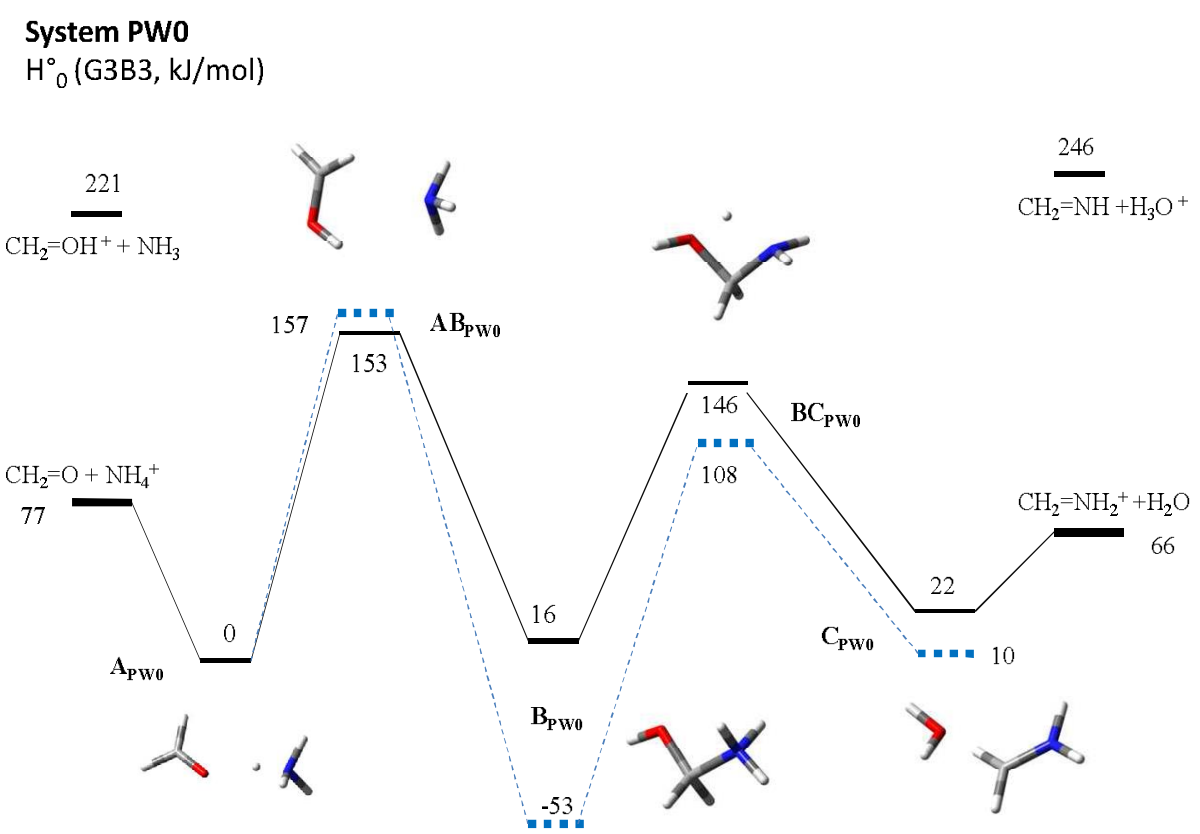

Figure 6. Zero Kelvin enthalpy profile for the PW0 system; dotted lines = CPCM/UAKS calculations.

ACS Paragon Plus Environment 
Modeling the First Step of the Strecker Synthesis

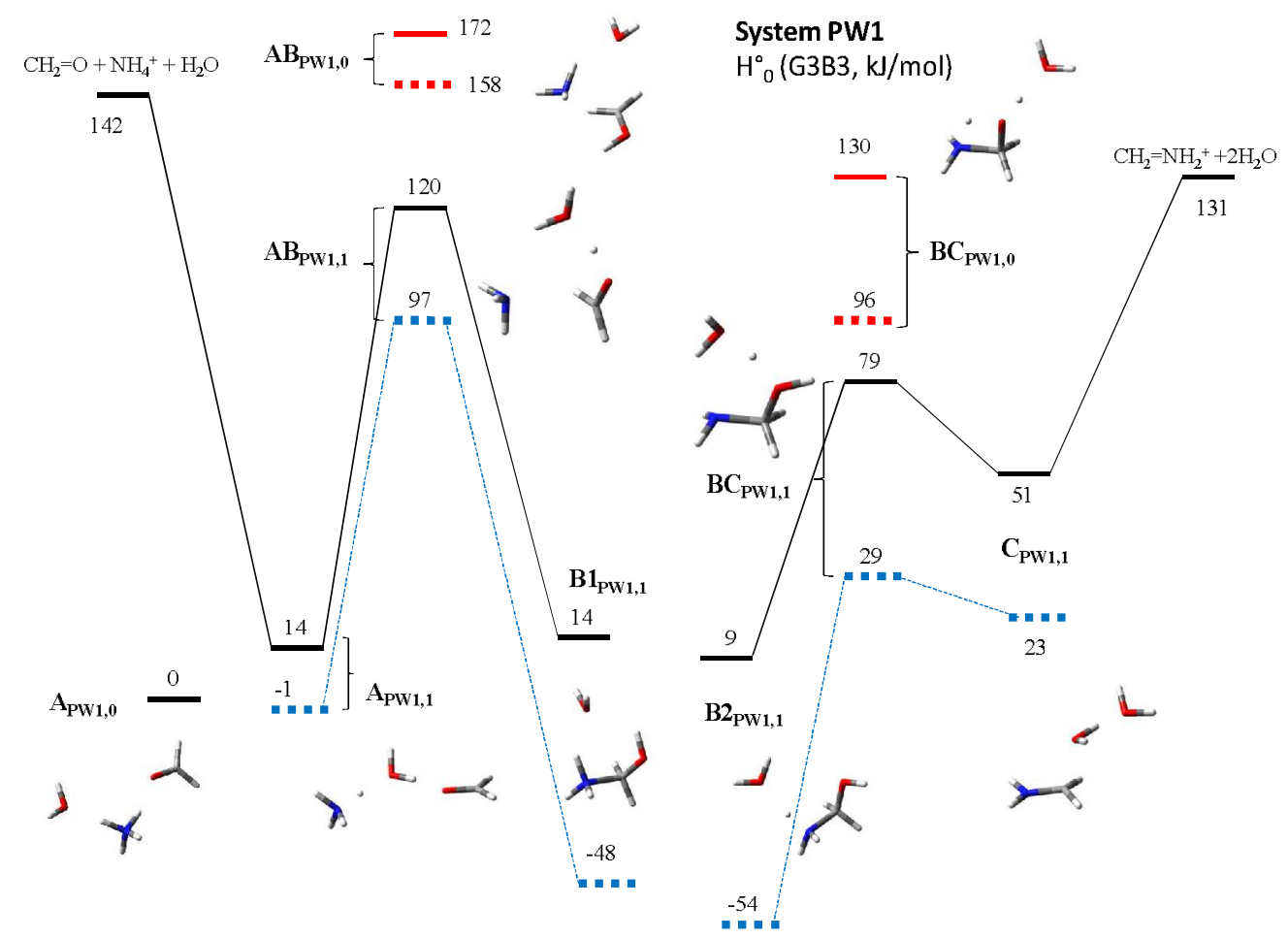

Figure 7. Zero Kelvin enthalpy profile for the PW1 system: (i) "active catalysis" by 1 water molecule (PW1,1), and (ii), no active catalysis but 1 water "spectator" molecule (PW1,0); dotted lines = CPCM/UAKS calculations. 


\section{System PW2}

$\mathrm{H}_{0}^{\circ}(\mathrm{G} 3 \mathrm{~B} 3, \mathrm{~kJ} / \mathrm{mol})$

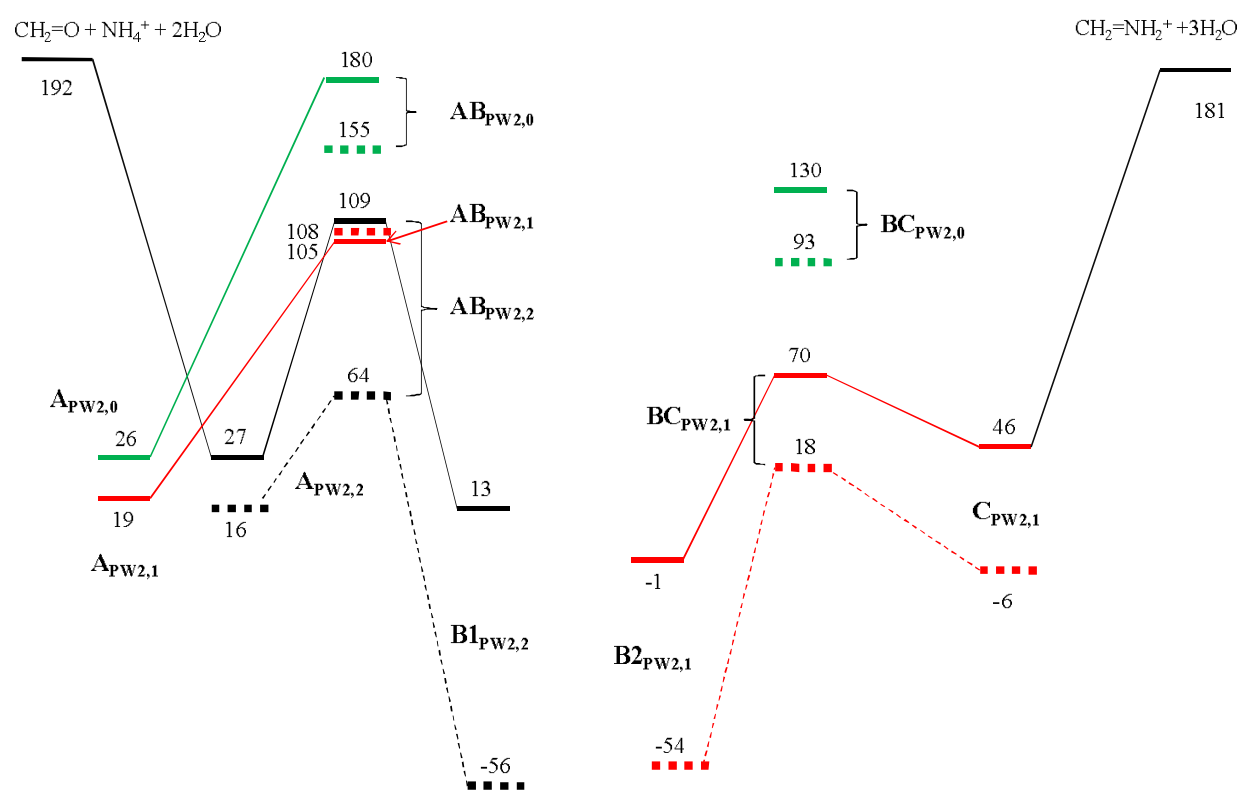

Figure 8. Zero Kelvin enthalpy profile for the PW2 system: (i) no active catalysis but 2 water "spectator" molecules, (PW2,0), (ii) "active catalysis" by 1 water molecule plus 1 water "spectator" molecule, (PW2,1), (iii) "active catalysis" by 2 water molecules (PW2,2); dotted lines = CPCM/UAKS calculations (for clarity, structures are presented separately in Figure SI4 of SI). 


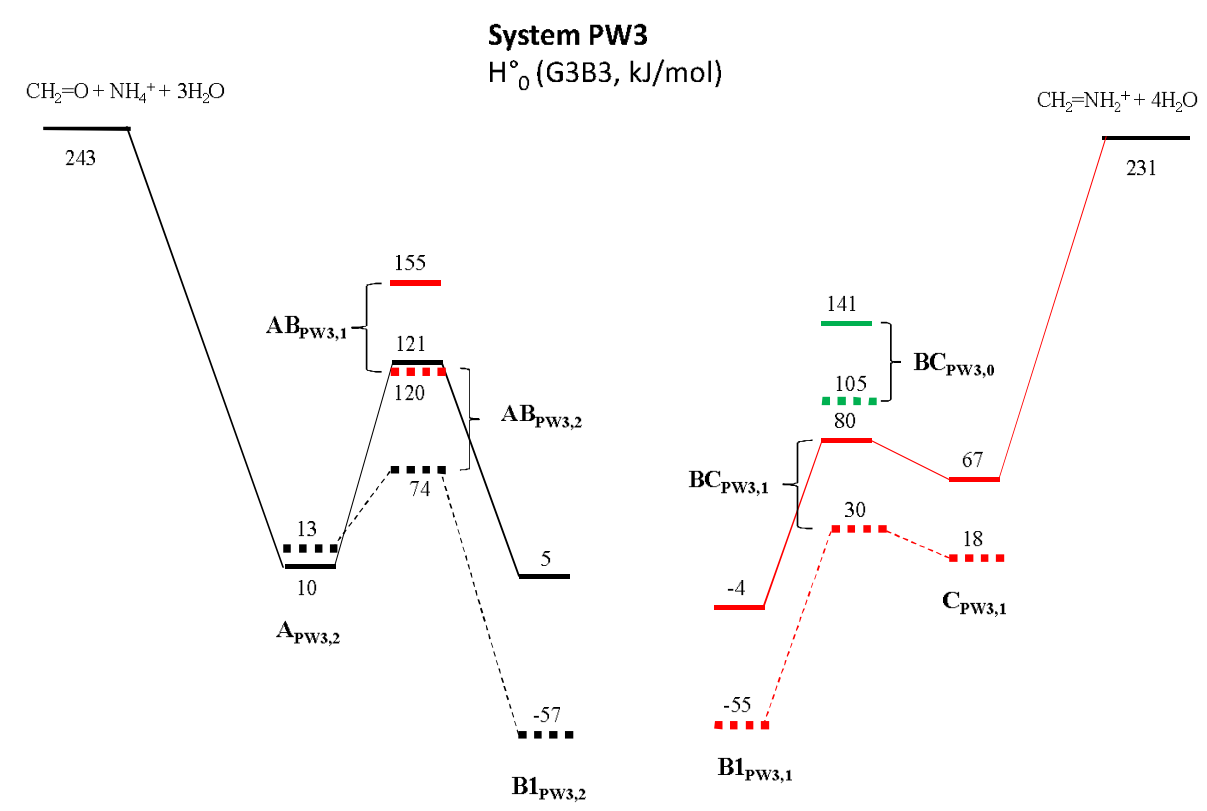

Figure 9. Zero Kelvin enthalpy profile for the PW3 system: (i) no active catalysis but 3 water "spectator" molecules (PW3,0), (ii) "active catalysis" by 1 water molecule plus 2 water "spectator" molecules ((PW3,1), (iii) "active catalysis" by 2 water molecules plus 1 water "spectator" molecule $(\mathbf{P W 3}, 2)$; dotted lines = CPCM/UAKS calculations (for clarity, structures are presented separately in Figure SI5 of SI). 


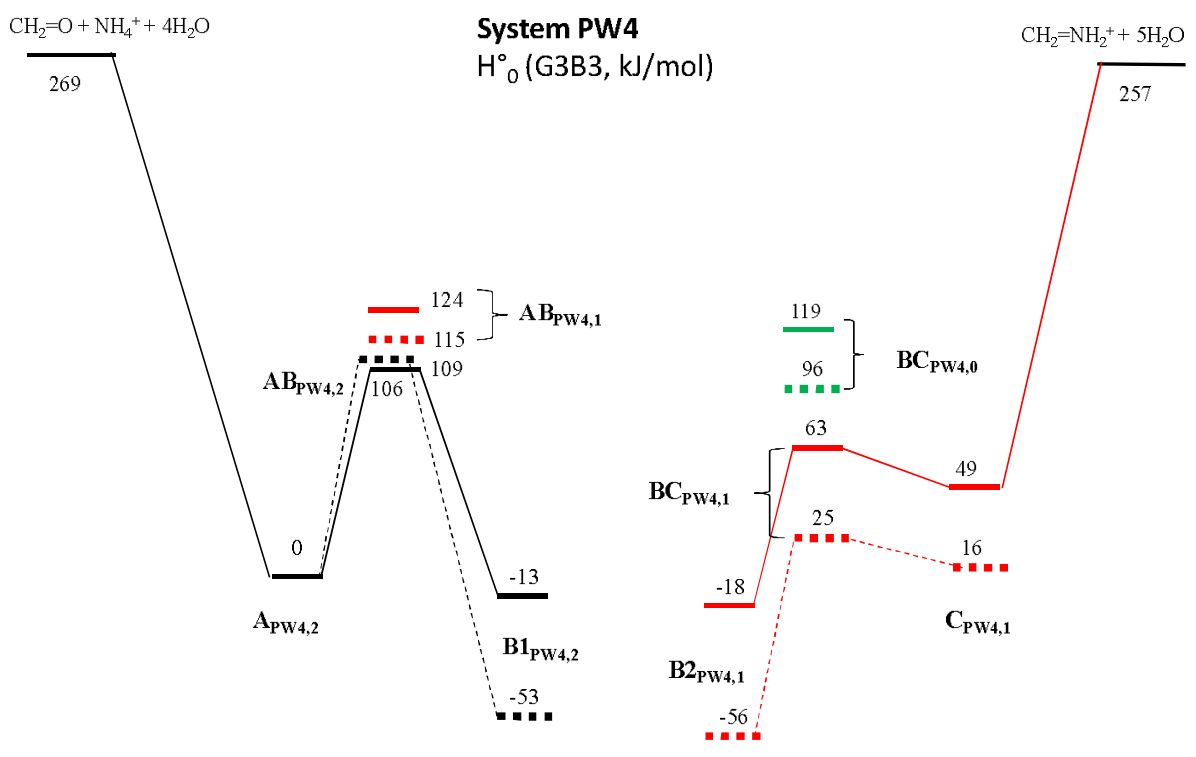

Figure 10. Zero Kelvin enthalpy profile for the PW4 system: (i) no active catalysis but 4 water "spectator" molecules (PW4,0), (ii) "active catalysis" by 1 water molecule plus 3 water "spectator" molecules (PW4,1), (iii) "active catalysis" by 2 water molecules plus 2 water "spectator" molecules $(\mathbf{P W 4 , 2})$; dotted lines = CPCM/UAKS calculations (for clarity, structures are presented separately in Figure SI6 of SI). 


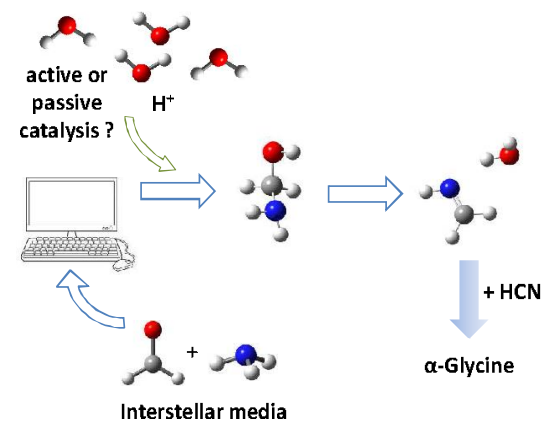

TOC Graphic 